Rhode Island College

Digital Commons @ RIC

$5-7-2019$

\title{
Diabetes Knowledge of Critical Care Nurses: A Quality Improvement Project
}

\author{
Sarah Christine Huley
}

Follow this and additional works at: https://digitalcommons.ric.edu/etd

Part of the Critical Care Nursing Commons

\section{Recommended Citation}

Huley, Sarah Christine, "Diabetes Knowledge of Critical Care Nurses: A Quality Improvement Project" (2019). Master's Theses, Dissertations, Graduate Research and Major Papers Overview. 302.

https://digitalcommons.ric.edu/etd/302

This Major Paper is brought to you for free and open access by the Master's Theses, Dissertations, Graduate Research and Major Papers at Digital Commons @ RIC. It has been accepted for inclusion in Master's Theses, Dissertations, Graduate Research and Major Papers Overview by an authorized administrator of Digital Commons @ RIC. For more information, please contact digitalcommons@ric.edu. 


\title{
DIABETES KNOWLEDGE OF CRITICAL CARE NURSES: A QUALITY IMPROVEMENT PROJECT
}

\author{
by
}

Sarah Christine Huley

A Major Paper Submitted in Partial Fulfillment

of the Requirements for the Degree of

Master of Science in Nursing

in

The School of Nursing

Rhode Island College

2019 


\begin{abstract}
Diabetes mellitus continues to become more prevalent in the United States, with approximately 1.5 million new cases diagnosed each year (ADA, 2018). Nurses play a key role in providing education to diabetic patients on the management of this disease. This encompasses a multitude of topics such as diabetic medications, treatments, and lifestyle choices that ultimately may aid in decreased morbidity and mortality otherwise associated with the disease and its co-morbidities. However, nurses' own perceived diabetes knowledge has been found to be overestimated when compared to actual nursing knowledge (Alotaibi, Ghlizadeh, Al-Ganmi \& Perry, 2017; Wakefield \& Wilson, 2014). Research also illustrates that the actual knowledge of diabetes care is suboptimal, and educational programs specifically tailored to diabetes management knowledge result in an improvement from pre-test scores with subsequent retention of the materials presented (Moattari, Moosavinasab, Dabaghmanesh, \& SarifSanaiey, 2014; Sweeney, Kenny and Schubert, 2013). The following literature review appraises current practice in diabetes management and evaluates literature regarding actual knowledge of nurses caring for inpatient diabetics. The purpose of this quality improvement project was to determine whether the implementation of a diabetic education program improves nurses' knowledge in the medical management, treatment, and care of the adult critical care patient with hyperglycemia. Results demonstrated variability in baseline knowledge and overall significant improvement in scores which validated the need for this program and may indicate a need to focus future educational programs on the care of the patient with diabetes.
\end{abstract}




\section{Acknowledgements}

There are so many people that contributed to the completion of this project that I would like to thank. First, the Miriam Hospital Nursing Administration for their support of the project, with special recognition to the managers and staff of the Specialty Care Unit (SCU). Also, many thanks to my first reader, Patti Calvert, second reader and Principal Investigator, Kara Misto, and third reader, Nancy Bushy for your commitment of time, energy, and patience throughout this process. All three of these individuals helped match my thoughts and ideas with local resources to guide me through this project. Lastly, thank you to my family for your support, encouragement, and for always being my biggest fan. 


\section{Table of Contents}

Background/Statement of the Problem .................................................................. 1

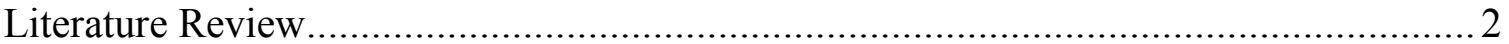

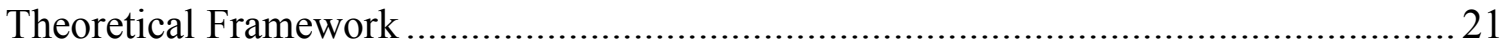

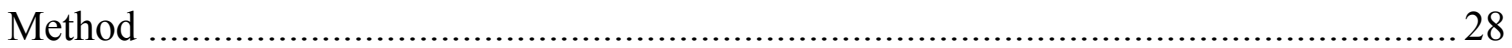

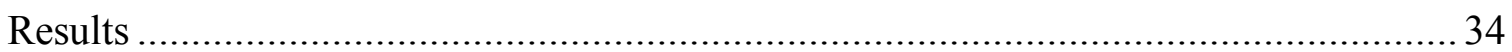

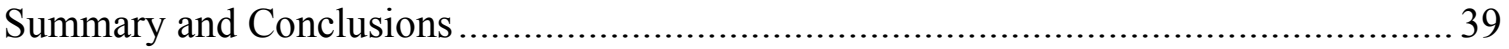

Recommendations and Implications for Advanced Nursing Practice ......................... 43

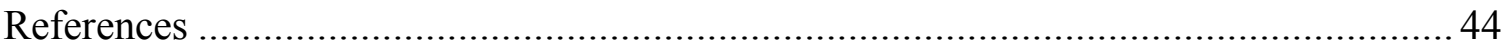

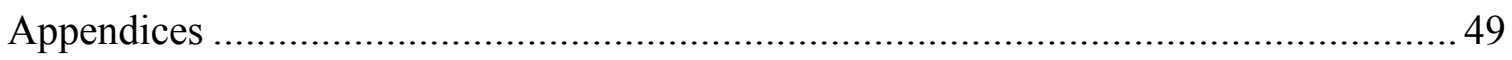


Diabetes Knowledge of Critical Care Nurses: A Quality Improvement Project

\section{Background/Statement of the Problem}

The diabetes mellitus (DM) epidemic continues to grow. The two primary types of diabetes in the adult acute care setting are type 1 and type 2 . Type 1 is typically found in a younger demographic, while type 2 is often a result of genetic, dietary, and lifestyle choices. A disease once thought to affect only older adults, Diabetes type 2 (DM II) has now become increasingly prevalent in younger patients as well. Optimal glucose levels along with control of both hyperglycemia and hypoglycemia is challenging, as is ensuring disease management compliance. To be successful at managing DM II, understanding the disease and its treatments are vital. A large portion of the education provided to patients is conducted by inpatient nursing staff. New diabetes medications and treatments become available every year, making it difficult to stay current with best practices. The ability to understand these drugs and treatments, what they do, and their side effects, requires a knowledge level to educate patients and family members and is a challenging task. How do we as a profession close any knowledge gaps that may exist? Would the implementation of an educational program related to hyperglycemia control improve the inpatient critical care nurse's knowledge in the medical management, treatment, and care of the critical care inpatient adult experiencing hyperglycemia? The purpose of this quality improvement project was to determine whether the implementation of a diabetic education program improves nurses' knowledge in the medical management, treatment, and care of the adult critical care patient with hyperglycemia. Next, a review of the literature will be discussed. 


\section{Literature Review}

A literature review was conducted utilizing the search engines of CINAHL and PubMed databases. Literature was searched from 2010 to current using the key words of diabetes, diabetes mellitus, nursing, education, knowledge, competency and nursing care, searched both individually and combined. Additional searches of CINAHL and Ovid using the key words of diab*, nurs*, knowledge, and educat* were conducted. The Cochrane database and the American Association of Critical Care Nurses were also reviewed for applicable literature. Results were further limited to English language print, the inpatient setting, and a measurable educational experience with nurses as the focus.

\section{Diabetes Mellitus: The Basics}

In 2015, over 30 million Americans had diabetes, with approximately 1.25 million children and adults having type 1 diabetes (ADA, 2018). Eighty-four million adults had prediabetes in 2015, which frequently leads to diabetes. In the United States (US), diabetes was the seventh leading cause of death in 2015. Seventy-nine thousand, five hundred thirty-five death certificates listed diabetes as the cause of death, 252,806 mentioned diabetes as a cause of death, yet diabetes still may be underreported as the cause of death. Only about $35 \%$ to $40 \%$ of people with diabetes who died had diabetes listed anywhere on the death certificate. Only $10 \%$ to $15 \%$ had it listed as the underlying cause of death (ADA, 2018).

As of 2017 , the total cost of diagnosed diabetes in the US was $\$ 327$ billion, with $\$ 237$ billion for direct medical costs and $\$ 90$ billion in reduced productivity. The 
average medical expenditures among people with diagnosed diabetes were 2.3 times higher than what expenditures in the absence of diabetes (ADA, 2018).

Race and ethnicity are factors in predicting diabetes risk, with the highest risk being among American Indians/Alaskan Natives (15.1\%). This is followed by Mexican Americans, non-Hispanic blacks (12.7\%), Hispanics (12.1\%), Puerto Ricans (12.0\%), and Asian Indians (11.2\%). All under 10\% are Cubans (9.0\%), Filipinos (8.9\%), other Asian Americans (8.5\%), Central and South Americans (8.5\%), Asian Americans (8.0\%), nonHispanic whites (7.4\%), and Chinese (4.3\%) (ADA, 2018). This prevalence of diabetes among all races and ethnicities directly impacts nursing care in the inpatient setting and requires nurses to be competent in caring for, treating, and educating patients with diabetes during their hospital admission.

\section{Pathophysiology}

Diabetes is a metabolic disorder in which there is an absence or insufficiency of insulin within the body. Glucose homeostasis is disturbed when insulin is inadequate or not present. The pancreas is responsible for the automatic release of insulin to move glucose from the bloodstream into cells. There are multiple categories or types of diabetes including Type 1, Type 2, and gestational diabetes (Childers \& Levesque, 2013). Type 1 diabetes is an autoimmune disease that requires daily exogenous insulin to sustain life. The disease results from a T-cell-mediated destruction of the beta cell resulting in absolute insulin deficiency. Type 2 diabetes is the result of a relative insulin deficiency secondary to insulin resistance (Grossman \& Porth, 2014). Thirty-seven percent of the United States population has prediabetes, defined as a hemoglobin A1c level of 5.7\%- 
$6.4 \%$ or a fasting glucose level of $100-125 \mathrm{mg} / \mathrm{dL}$. Approximately $70 \%$ of these 86 million prediabetics are expected to progress to type 2 diabetes within 10 years (DeJesus et al., 2017). This disease may be controlled with lifestyle changes or oral medications, but may also require insulin. Gestational diabetes is present during pregnancy and can increase the overall risk for development of type 2 diabetes. Although type 1 diabetics have a higher risk, type 2 diabetics are also at risk for Diabetic Ketoacidosis (DKA), a state of severe hyperglycemia, hyperketonemia, and metabolic acidosis due to absolute insulin deficiency (Grossman \& Porth, 2014).

In the critical care environment, the stress of acute and critical illness causes a systemic response which results in a rise in plasma glucose, pro-inflammatory cytokine release, and counterregulatory hormone levels. This contributes to the systemic inflammatory response and development of insulin resistance which is often found with acute and critical illness (Jivanji, Asrani, Windsor \& Patrov, 2017). While normoglycemia may not always be obtained, it is necessary to tailor care to each patient while hospitalized. An individualized plan of care can prevent the adverse outcomes that occur with hyperglycemia in the hospitalized patient (Childers \& Levesque, 2013).

\section{Diabetes Mellitus and Hyperglycemia}

Background. Hyperglycemia is an independent risk factor for adverse health outcomes with the potential for poor outcomes in patients admitted to the hospital (Childers \& Levesque, 2013). In a systematic review with meta-analysis by Jivanji, Asrani, Windsor, and Patrov (2017), all available clinical evidence was reviewed on the association between in-hospital glucose concentration levels and the development of 
new-onset diabetes post-discharge in acute and critically ill patients. The systematic review included 23 studies with more than 120,000 patients, with 18 of the studies meeting the eligibility criteria for meta-analysis. Inclusion criteria included were diabetes onset after hospitalization, no history of diabetes, older than 17 years, and hospital admission with acute and critical illness. Exclusion criteria were in-hospital glucose concentration not reported, pediatric or transplant patients, and review, commentaries, and letters to the editor. The subjects included in the review were relatively homogenous, with no history of diabetes prior to or during their hospital stay. Results suggested that the degree of hyperglycemia in acute and critically ill patients increases the susceptibility to new-onset diabetes. This study found that the severity of hyperglycemia during hospitalization was significantly related to the development of new-onset diabetes. In-hospital glucose concentration was 4\% (95\% CI, 2\%-7\%) for patients with normoglycemia, $12 \%(95 \% \mathrm{CI}, 9 \%-15 \%)$ for patients with mild hyperglycemia, and $28 \%$ (95\% CI, 18\%-39\%) for patients with severe hyperglycemia. (Jivanji et al., 2017).

Causes of Hyperglycemia. Freeland (2016) stated factors contributing to the development of hyperglycemia in hospitalized patients include: increased secretion of counterregulatory hormones due to stress; infection; acute illness; surgery; nutrition; IV dextrose; medications that induce hyperglycemia; missed insulin doses; late insulin doses; use of sliding scale insulin regimens only; decreased exercise and inadequate knowledge of the management of hyperglycemia and diabetes by health care providers. Stress causes increased cortisol, catecholamines, glucagon, growth hormone, 
gluconeogenesis, and glycogenolysis, all of which are key components leading to increased glucose levels (Freeland, 2016).

Recommendations. Glycemic recommendations are varied and should always be individualized to the patient. The American Diabetes Association (ADA) recommends a pre-prandial glucose of 80-130 mg/dL (ADA, 2018). The Endocrine Society's most recent guidelines based on research by Umpierrez et al. (2012) recommend a pre-prandial blood glucose of $<140 \mathrm{mg} / \mathrm{dL}$. Both concur that the target random blood glucose level is $<180 \mathrm{mg} / \mathrm{dL}$, although a lower target may be able to be set for a patient at less risk for a hypoglycemic event. The 2018 ADA Standards of Medical Care recommend a HbA1c of less than $7.0 \%$ to reduce the incidence of microvascular disease. It is also considered reasonable to suggest an $\mathrm{HbA} 1 \mathrm{C}<6.5 \%$ for select individuals if significant risk for hypoglycemia or other adverse effects of treatment is not present (ADA, 2018). While lower glucose levels were once the accepted standard, it is now known that this results in a larger number of hypoglycemic episodes. Blood glucose levels of less than $40 \mathrm{mg} / \mathrm{dL}$ can cause near double the risk of mortality (Childers \& Levesque, 2013).

Management. Medication regimen management is integral to the care of the inpatient diabetic/hyperglycemic patient. The ADA no longer supports the use of sliding scale insulin, but rather basal insulin with bolus doses (ADA, 2018). The body makes a basal rate of insulin at a steady state regardless of food intake to maintain consistent glucose levels. Additionally, the pancreas secretes insulin in response to food intake, provided there is remaining insulin to secrete (Freeland, 2016). The ADA recommends basal insulin with bolus doses as the standard for the care of diabetes in the hospital setting, as continuous insulin infusions may not be practical in all inpatient settings and 
often restricted to critical care settings only. Diet control with healthy weight maintenance, lifestyle changes, oral medications, and insulin regimens are some of the other methods commonly proposed when aiming to control hyperglycemia (ADA, 2018).

A newly diagnosed type 1 diabetic with diabetic ketoacidosis, a type 2 diabetic with severe dehydration or hyperosmolar hyperglycemic states (HHS), and a patient with medication-induced hyperglycemia will all require different goals and will have individual requirements of their nurses (Keaveny, 2013). The American Association of Diabetes Educators (AADE, 2017) has identified seven self-care behaviors to include when providing education to the diabetic population. These self-care behaviors are healthy eating, being active, monitoring blood glucose, taking medication, problem solving hypo-/hyperglycemia, healthy coping, and reducing risks of developing other health problems and have all been found to help aid in coordinating the multifaceted and individualized education needs of diabetic patients (AADE).

\section{Hyperglycemia in the Critical Care Environment}

Critically ill patients have a much higher incidence of hyperglycemia in comparison to the general medical population, with at least 50\% of Intensive Care Unit (ICU) patients experiencing hyperglycemia (Faust, Attridge, \& Ryan, 2011). These elevated blood glucose concentrations are known to be associated with adverse outcomes. While glucose control is a desirable outcome, the increased mortality rates incurred with hypoglycemia must be balanced with the potential decreased mortality rates accompanying tight glycemic control (Faust et al.). 
Critically ill patients experiencing hyperglycemia may not have preexisting diabetes. Conditions such as infection, sepsis, shock, trauma, total parenteral nutrition, and older age are all contributing factors to the development of acute elevations in blood glucose (Grossman \& Porth, 2014). These trigger the stress response and subsequent release of stress hormones linked with hyperglycemia. The pathophysiological consequences of hyperglycemia are thought to stem from 3 proposed mechanisms: immune system dysfunction with reduced phagocytic abilities, extreme insulin resistance leading to oxidative damage, and endothelial cells changing from production of nitric oxide to production of reactive oxygen species that cause apoptosis, nucleic acid damage, and protein denaturation (Lee \& Halter, 2017).

Another factor contributing to poor outcomes in the diabetic patient is wide shifts in blood glucose, as this results in a higher mortality rate than patients without these highly varied blood glucose levels (Faust et al., 2011). In 2017, both the ADA and the American Association of Clinical Endocrinologists (AACE) issued consensus guidelines for the blood glucose control of critically ill patients. Blood glucose targets for critically ill inpatients (ADA/AACE) are a treatment threshold of $>180 \mathrm{mg} / \mathrm{dL}$, goal 140-180 $\mathrm{mg} / \mathrm{dL}$ for most patients, a lower threshold of $110 \mathrm{mg} / \mathrm{dL}$ for selected, low-risk patients, and hypoglycemia defined as $<70 \mathrm{mg} / \mathrm{dL}$ (ADA, 2018; AACE, 2018). Advocacy for algorithm-based treatment is preferred to avoid large shifts in blood glucose and to reduce the number of hypoglycemia episodes. This remains consistent with the current blood glucose management guidelines (ADA, 2018; AACE, 2018). Next, the disease process will be further focused on two specific hyperglycemic emergencies frequently requiring inpatient care. 


\section{Diabetic Ketoacidosis (DKA)}

Diabetic ketoacidosis is a state of insulin deficiency combined with an increase of insulin-antagonistic hormones resulting in the altered metabolism of carbohydrates, fats, and proteins. Decreased insulin levels and increased insulin resistance result in excess glucose production. Additionally, there is increased synthesis of ketones and lactic acidosis resulting in ketosis and metabolic acidosis. This causes fluid and electrolyte imbalances that lead to the development of the signs and symptoms of DKA: blurred vision, diminished level of consciousness, nausea, abdominal cramping, vomiting, polyphagia, polyuria, polydipsia, fatigue, weakness, muscle cramps, fruity odor to breath (ketosis), tachycardia, orthostatic hypotension, tachypnea, and Kussmaul respirations. The hallmark clinical findings of DKA is the combination of hyperglycemia, a low serum bicarbonate, and an elevated anion gap (Sanuth, Bidlencik \& Volk, 2014). While DKA is a very serious complication of diabetes, HHS is a life-threatening hyperglycemic emergency frequently requiring inpatient critical care.

\section{Hyperosmolar Hyperglycemic State}

Hyperosmolar hyperglycemic state is a life-threatening hyperglycemic emergency. While there may be some insulin present, there is not enough to prevent hyperglycemia, and glucose transport across the cell membranes is impaired. Like DKA, hyperosmolality results, but fluid shifts from intracellular to extracellular spaces to offset this. Therefore, fluid deficits are much more severe than in DKA, as are electrolyte losses (Sanuth, Bidlenicik \& Volk, 2014). Lethargy, fatigue, polydipsia, polyuria, polyphagia, flushed skin and dry mucous membranes, tachycardia, hypotension, shallow, 
rapid respirations, and ultimately coma results from the cellular dehydration (Grossman \& Porth, 2014). The plasma glucose is often $1000 \mathrm{mg} / \mathrm{dL}$ or higher without the presence of ketosis. The altered mental status can result in coma when the plasma tonicity rises above $330 \mathrm{mOsm} / \mathrm{kg} \mathrm{H} 2 \mathrm{O}$ (Sanuth, Bidlencik \& Volk, 2014).

Hyperglycemia, if not controlled, leads to increased morbidity and mortality in the critical care patient. Bedside nurses are heavily involved in the management, treatment, and care of the critical care adult inpatient experiencing hyperglycemia. Nurses' comprehensive knowledge of the pathophysiology of diabetes is required to provide quality, safe care to the critical care patient population. Next, the knowledge of nurses providing care for patients with diabetes will be discussed utilizing specific studies focused on the results of educational interventions conducted and the nurse's understanding of diabetes in the inpatient environment.

\section{Nurses' Knowledge of Diabetes Management}

The recognition of gaps in diabetes knowledge was identified as early as 1967 by Etziler after the realization that the lack of patient understanding of the diabetes disease process was correlated to a lack of their health care provider's understanding. In the Etziler study, this was generalized to the entire health care community that provided education to the diabetic patient (1967). In 1983, Scheiderich, Freibaum, and Peterson identified that nurses, as the primary educators of patients with diabetes upon discharge from care, did not have a consistent level of knowledge of the diabetes process and management of the disease. They conducted a study with 137 volunteer registered nurses within 3 Midwest hospitals: a 300-bed community suburban; a 350-bed community urban 
hospital; and a 1000-bed medical center hospital. The authors identified that the diabetes knowledge test used in the Etziler study needed modification to ensure test questions were compatible with current information. A panel of five expert nurse diabetes educators with postgraduate education and experience reviewed the 34 questions for clarity, accuracy, and essentiality. The test was administered to registered nurses (RNs) on medical or surgical units where patients with diabetes were admitted. Limitations included that nurses had to be licensed, not on night shift, a head nurse, or had any formal postgraduate diabetes education. There were no limitations on age, experience, type of employment, or foreign education. Two hundred thirteen nurses were selected for participation, with a maximum of 10 nurses per unit. One hundred thirty-seven nurses returned the tests, for a return rate of $64 \%$. Although the option to take the test home was available, all nurses opted to complete the material during their assigned shift (Scheiderirch et al., 1983).

A mean score of $74 \%$ was achieved, with $30 \%$ of nurses $(n=41)$ scoring less than $70 \%$ on the test. This is especially concerning considering $82 \%$ of the test groups $(\mathrm{n}=112)$ reported having done little patient education on diabetes in the month prior, although $40 \%(n=55)$ of respondents had cared for $>5$ patients with diabetes during the same time period (Scheiderich et al., 1983). The authors concluded that expert diabetes educators should be more consistent in sharing their knowledge with staff and that other health care workers that rely on nurses to provide diabetes discharge education be cognizant of these potential knowledge limitations. Despite these findings occurring over 30 years ago, the knowledge needs of staff nurses at the bedside continue to be a relevant problem. 
Trepp, Wille, Wieland, and Reinhart (2010) published the results of a crosssectional study conducted in Chur, Switzerland. Physicians, nurses, medical students and student nurses from the departments of internal medicine, surgery, and gynecology from a regional hospital as well as tertiary care center were surveyed using a 42-item anonymous questionnaire. The questionnaire was generated from validated questionnaires, translated into German and adapted to local drug specifications where appropriate. The participants were also asked how secure they felt in managing the inpatient with diabetes (comfort level: 1 [very insecure] - 6 [very secure]). Reliability and internal consistency of the questionnaire were evaluated by Chronbach's Alpha (0.75) and item-total correlation (0.01-0.43). Non-parametric Spearman rank correlation was used to determine the correlation between comfort and achieved scores with a pvalue of $<0.05$ being considered significant (Trepp et al.). Twenty questions were identified as addressing basic diabetes knowledge and the remainder were grouped into subscales: insulin therapy; hypoglycemia; ketoacidosis; oral hypoglycemic agents; and targets of diabetes management (Trepp et al.). Results discussed will be limited to results obtained from the nurses who participated in the study.

A total of 314 nursing staff were provided the questionnaire with 161 completed returned questionnaires obtained $(\mathrm{n}=161)$. Nurses in internal medicine $(\mathrm{n}=52)$ and surgery $(\mathrm{n}=65)$ had the same level of knowledge $(41 \pm 11 \%)$ which was comparable to student nurses' knowledge ( $40 \pm 9 \%, \mathrm{n}=12)$. Nurses in gynecology had lower total scores $(30 \pm 10 \%, \mathrm{p}<0.001)$. The highest subscale scores were achieved in the subscale addressing hypoglycemia $(59 \pm 25 \%)$. However, the lowest subscale scores were achieved in the subscale of ketoacidosis $(27 \pm 19 \%)$. Nurses in internal medicine and 
surgery scored the highest in comfort level $(4.2 \pm 1.0)$ despite these test findings (Trepp et al., 2010).

The findings from this study did address some advanced knowledge in addition to basic diabetes-related knowledge questions. The overall $43 \%$ correctly answered questions speaks to the actual knowledge of the inpatient staff. The significantly low correctly answered questions of nurses regarding ketoacidosis suggests topics beyond basic diabetes care were not common knowledge. Also, scores did not improve between student nurse and staff nurse, which suggests inadequate continuing education postgraduation and supports the need for ongoing diabetes education of inpatient nursing staff (Trepp et al., 2010).

In 2014, Modic, Vanderbilt, Siedlecki, Sauvey, Kaser, and Yager conducted a descriptive, correlation study to determine what bedside nurses knew about diabetes management in a 1200 bed health care center in the Midwest. Their goal was to determine the comfort, familiarity, and knowledge of inpatient diabetes management principles. Prior to the educational intervention, a needs assessment was conducted. (based on the needs assessment), Four key focus areas were selected for four-hour educational intervention: hyperglycemia; insulin therapeutics; hypoglycemia prevention and management; and diabetes survival skills. The specific aims were to identify any relationship between age and level of knowledge, years of experience and knowledge, self-rated comfort and familiarity and knowledge, and/or a gain in knowledge of inpatient diabetes management principles after completion of the educational session. Knowledge levels were tested with the Diabetes Management Knowledge Assessment Tool (DMKAT), designed after a literature review. This measure included 20 multiple choice 
questions with five questions in each area identified from the needs assessment. Completed pre- and post-tests were collected by the researchers and submitted into SPSS for data analysis. The course was offered as face to face sessions with 32 separate sessions over a four-month period, resulting in a convenience sample of 2250 nurses. Nurses were clinically active in any role, including staff nurse, nurse manager, clinical instructor, or clinical nurse specialist (Modic et al.).

Due to the large sample size, the paired t-test was set to 0.01 . Data analysis from the pre- and post-tests showed a negative correlation using Pearson's correlation in which scores decreased with age $(r=-0.182 ; \mathrm{p}=<0.001)$ despite the previously found correlation between age and increased education and experience. No difference in level of knowledge was noted based on education $(r=-140 ; p<0.001)$ or years of experience $(\mathrm{r}=0.759 ; \mathrm{p}<0.001)$ using Spearman's correlation. There was no significant relationship between individual comfort $(\mathrm{r}=0.002 ; \mathrm{p}=0.912)$ or individual familiarity $(\mathrm{r}$ $=-0.013 ; \mathrm{p}=0.556)$, but there was when comfort and familiarity were combined $(\mathrm{r}=$ $0.706 ; \mathrm{p}<0.001)$ in relation to diabetes knowledge. Finally, there was a significant increase in pre- $(\mathrm{x}=11)$ and post-test $(\mathrm{x}=20)$ scores after the educational intervention of the 4-hour diabetes management course. This study factored in subspecialties and also showed that regardless of education or age, nurses were not current in inpatient diabetes management throughout the spectrum of subspecialties, making the findings more generalizable. Despite educational efforts, insulin regimens were noted to be problematic, suggesting a need for additional diabetes education resources for daily questions that may arise (Modic et al., 2014). 
In a study by Wakefield and Wilson (2014), a prospective, randomized control trial was used to determine whether a comprehensive self-paced online hospital-nurse diabetes education course would improve test scores for both factual and applied diabetes knowledge. Also, of interest was whether the increased test scores would be retained three months after completion of the course, as well as the relationship of diabetes education to hospital nurses' perceived confidence in their knowledge and performance of key components of diabetes care. All initial 202 participants were direct care inpatient nurses at a community based nonprofit medication research foundation in south Texas with both urban and rural settings. Participants were blinded, then randomly and equally assigned to either an intervention group or control group. The intervention group was measured at three intervals: pre-course, post-course; and three months after completing a 4.2-hour interactive, self-paced, audio PowerPoint online educational course. The course was developed by an endocrinologist/educator, two certified diabetes educators, and a chronic disease management physician. The control group was measured pre- and postcourse and was also later offered the course for continuing education. Attrition was minimized as much as possible, but of the 160 that logged on to start, two removed themselves, 13 terminated employment, 36 did not finish, and four had missing data (Wakefield \& Wilson, 2014).

There were no correlations between test scores and the level of nursing educational degree and/or the years of nursing experience of work within the hospital system. Both groups scored better on test part 1 factual knowledge (66.3\%) than test part 2 application of knowledge (46.6\%). There was little difference between the groups' pretest combined scores, but post-test the intervention group (69.7\%) did significantly better 
than the control group (55.5\%). There was a significant gain in raw mean scores of $35 \%$ for the combined tests. The effect size was considered very large for educational intervention (0.97). There were no noted differences in test scores between hospitals within the system despite urban and rural settings. There was also significant retention of knowledge based on three-month test scores. Part 1, factual knowledge scores remained at $75.4 \%$ at three-months as compared to the immediate post-test score $(80.4 \%)$. Part 2 , applied knowledge scores increased to $59.0 \%$ at three months as compared to the immediate post-test score $(57.8 \%)$. The authors did not question whether the nurses had performed any other diabetes education courses during the time period under study. The difference in scores showed that there was an additional need for education in the application of knowledge versus factual knowledge. The nurses' perceptions based on the Likert scale was "almost completely confident" with their knowledge of diabetes care despite the group's mean pre-test scores of $51 \%$. The subspecialties of the nurses were not revealed, which could impact reproducibility and generalizability (Wakefield \& Wilson, 2014).

Alotaibi, Ghlizadeh, Al-Ganmi and Perry (2017) examined perceived and actual diabetes knowledge among nurses working in a Saudi Arabian, tertiary hospital in a mixed-method study. They noted that researchers had not yet studied whether there was a difference between the perceived diabetes knowledge of nurses and the actual, measured knowledge of nurses. The majority of nurses practicing at the facility in the study were not native Saudis nor did they obtain their education in Saudi Arabia, but instead were comprised of nurses recruited from Australia, the UK, India, the Philippines, South Africa and the United States. The researchers noted that this presented a very 
diverse group of nurses for their study. The goal of the study was to identify nurses' perceived knowledge and skills and assess the accuracy of the actual knowledge, examine the relationships between actual and perceived knowledge, and identify any factor predicting these relationships. This article focused only on the quantitative phase of the multi-phase study conducted at the largest hospital in the capital of Saudi Arabia. This was conducted after completion of a 15-nurse pilot study from their staff education department, who were otherwise ineligible for the study. Target sample size was calculated to be 700 and restricted to nurses with at least six months work experience in direct care (Alotaibi, Ghlizadeh, Al-Ganmi \& Perry, 2017).

Tools used for data collection were a self-report questionnaire, the diabetes selfreport tool, and the diabetes basic knowledge tool which was modified with four additional questions from other validated tools. These were reviewed for content by experts from four nations and modified for understanding to achieve a content validity of greater than 0.98 . Tests were completed with a 10-day interval between pre- and posttests and included nurses from 5 subspecialties. Of the 700 original surveys, 500 were returned, with 77 incomplete and 423 completed. (Alotaibi et al, 2017).

Perceived knowledge was assessed using the Diabetes Self-Report Tool, a questionnaire developed to assess nurses' perceived knowledge of diabetes care. The measure included 15 questions with responses using a Likert-type scale format ranging from 1 (strongly agree) to 4 (strongly agree). Various diabetes-related content areas such as diabetes pathology and symptoms, medications, foot and surgical care, blood glucose management, diet and complications were included. The maximum possible score was 60; response scores ranged from 30 to 60 , with a mean (SD) score of 46.9. This 
represents an equivalent score of $78.2 \%$, or 3 ('agree'), which indicated that the perceived knowledge scores were generally positive (Alotaibi et al, 2017). However, the diabetes basic knowledge test (DBKT) demonstrated a mean score of $52.3 \%$, with $80.0 \%$ considered the minimum required score for acceptable knowledge levels (Alotaibi et al, 2017).

Analysis showed a higher perceived knowledge $(\mathrm{t}[2.94], \mathrm{p}=0.003)$ by male nurses with lower actual knowledge scores $(\mathrm{t}[-1.95], \mathrm{p}=0.02)$ than their female counterparts. Nurses that currently were providing care for patients with diabetes, attended any diabetes professional development program, or had access to diabetes policies and guidelines also had a higher perceived knowledge level. The higher the education, the higher correlated perceived and actual knowledge scores. Diploma nurses $(n=56)$ scored a mean score of 45.4 , while bachelors prepared nurses $(n=353)$ achieved a mean score of 46.9 , and master's prepared nurses $(n=14)$ achieved a mean score of 49.7 (Alotaibi et al, 2017).

The sample of nurses native to Saudi Arabia $(n=30)$ were found to achieve overall lower scores. Nurses who received their education in Saudi Arabia scored a mean of 20.6 on actual diabetes knowledge compared to the mean of 24.1 of all other countries (Philippines; India; other). Native Saudi Arabian nurses had a perceived diabetes knowledge mean of 43.6 compared to the mean of 46.3 of all other countries. Of note, Saudi Arabian nurses scored the overall lowest in both actual and perceived diabetes knowledge. This study makes the idea that perception of knowledge is greater than the actual knowledge of nurses in the care of the diabetes patient more generalizable. This is 
due to its inclusion of multiple specialties as well as its use of nurses from multiple countries (Alotaibi et al, 2017).

\section{Measuring Nurses' Knowledge}

Many instruments have been utilized to measure nurses' diabetes knowledge. The most commonly used instruments for measurement of the diabetes knowledge are the Diabetes Basic Knowledge Test (DBKT) and the Diabetes Self-Report Test (DSRT). These two tests were used in the descriptive, correlation study by Modic, Vanderbilt, Siedlecki, Sauvey, Kaser, and Yager (2014) to determine what bedside nurses know about diabetes management. However, Francisco (2013) found that the DBKT and DSRT do not consistently report reliability and validity measures.

The Diabetes Knowledge Test has also been tested for reliability and validity (Fitzgerald et al, 2016). The DKT consists of 23 knowledge-based test items developed by the Michigan Diabetes Research Training Center (MDRC) and represent a general knowledge of diabetes. A difficulty index, reliability information, and an item to group total correlation is provided for each item by MDRC. The Michigan Diabetes Research Training Center notes that it is essential to evaluate the DKT for item-to program content match. The 23-item test takes approximately 15 minutes to complete (MDRC, 2017). The DKT can also be modified using a true/false scale for ease of administration and understanding (Collins, Mughal, Barnett, Fitzgerald \& Lloyd, 2011). However, the DKT addresses only basic diabetes knowledge and does not address the advanced knowledge requirement of nurses providing care in the critical care environment. 
These studies demonstrated that there is a need for additional diabetes education and that focused diabetes educational sessions improve nursing knowledge. Despite each study having used a different test of actual diabetes knowledge to determine nursing knowledge of diabetes, the results were similar. However, this literature search resulted in no such studies or testing tools that focused on the advanced nursing knowledge required for the care of the diabetic adult inpatient in the critical care environment. Next, the theoretical framework will be discussed. 


\section{Theoretical Framework}

This quality improvement project will utilize two models as the theoretical framework of the project. The first is the Logic Model, also known as the theory of change, and is a systematic method of developing a program (W.K. Kellogg Foundation, 2004). The Logic Model fits the clinical question of whether a diabetic education program improves nursing knowledge in the medical management, treatment, and care of the adult inpatient diabetic. The Model flows in a step-wise fashion and produces measurable outcomes. Planning is specific and involves stakeholders to assist and ensure best implementation to achieve the desired outcomes with minimal unintended outcomes within the expected timeframe (Morzinski \& Montagnini, 2002). The Model can be applied to outcomes within a topic under review, ranging from simple to complex. In the evaluation of educational programs, a needs assessment can help set the program design as well as determine related expected outcomes. Key to implementation and application of the Logic Model is the inclusion of all stakeholders to help identify expected and unintended outcomes, barriers to completion, and the overall goal of the program (Van Melle, 2016). All planning requires assumptions and outcomes are based on if...then statements (W. K. Kellogg Foundation, 2004).

Essential to the model are a few key steps: input/factors, activities, outputs, outcomes, and impacts (W.K. Kellogg Foundation, 2004; Figure 1). Input/factors are resources and/or barriers that can either enable or limit the effectiveness of your program. Activities can include processes, tools, products, services, and infrastructures within the planned program. Outputs are the objective measures captured from the program activities or the direct results. Outcomes are the changes expected from program 


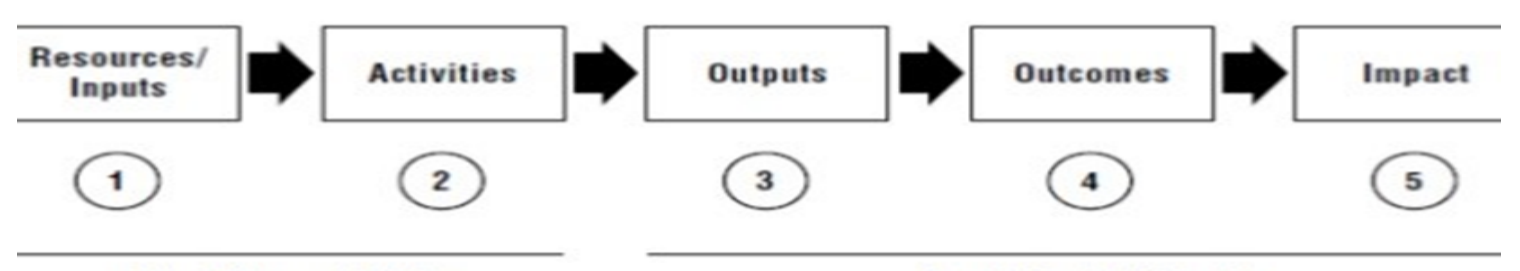

Your Planned Work

Your Intended Results

Figure 1. The Logic Model. W. K. Kellogg Foundation, 2004.

activities, usually at the individual level. Impacts are changes expected at the system level. Outcomes and impacts should be SMART: Specific; Measurable; Action-oriented; Realistic; and Timed. These steps allow for an inventory of what is needed for the program, a method for describing why the program will produce the intended outcomes and a method for program management, assessment, and reassessment (W. K. Kellogg Foundation, 2004).

The Logic Model can be useful in quality improvement projects, allowing precise communication about those aspects of the program that would benefit from evaluation findings. Stakeholders are able to revisit and revise their logic models as often as necessary. The Model allows for evaluation of the program that serves to demonstrate accountability, produce a shared understanding of the program and intended outcomes, capture processes through documentation, and document/track progress towards outcomes (CDC, 2009). The Model also allows for visual representation which provides flexibility, identification of strengths and/or weaknesses, and "run through" scenarios to 
identify unintended or undesired outcomes allowing for modification as needed (W. K. Kellogg Foundation, 2004).

There are various approaches to Logic Models such as the Theories Approach, Outcomes Approach, and Activities Approach Models (W.K. Kellogg Foundation, 2004). The Theory Approach Model emphasizes the theory of change that provides explanation of the reasons for the design and plan for the program, such as grant proposals. The Outcomes Approach Model focuses on program planning, often subdividing outcomes and impact over time, such as designing effective evaluation and reporting strategies. The Activities Approach Models focus on the implementation process, providing the detailed steps needed to follow in order to implement a program, used to inform management planning activities (W. K. Kellogg Foundation).

The Logic Model is sufficiently rich and detailed in that, if further processes were added, it may become too specific and not allow for the adaptability that it currently provides. This also may result in over-simplification, causing unintended or unmet outcomes. The theory is useful in explaining phenomena based on if...then statements and assumptions (W. K. Kellogg Foundation, 2004). While the model is being viewed from the nursing standpoint, it is applicable to many other fields such as social work, community health or business planning. It is also useful within many domains of nursing: education; institution of new policies/methods; and management.

Research based on this theory could answer critical questions for nursing. In the research by Paquette-Warren, Roberts, Fournie, Tyler, Brown, \& Harris (2014), it was noted that evaluation studies of quality improvement initiatives often fail to capture 
details about program activities, the implementation process, and the perceptions of the stakeholders so that clear inferences about program impact can be made. The Logic Model was applied to various program activities, with the goal of providing a visual representation of implementation and effectiveness measures within an interprofessional group in primary care. This consisted of 13 varying health professionals caring for chronically ill patients. Three qualitative methods were used including program documentation, participant observation, and in-depth interviews. The aim was to capture a reproducible method of implementation that could be useful in transitioning evidence into practice on a large scale. Findings revealed that both classroom and workplace learning combined with changes during implementation, a series of off-site/classroom learning sessions, and practice-based/workplace IT support and practice coaching were the most effective elements and facilitate drawing causal inferences between the program and outcomes (Paquette-Warren et al., 2014).

In the research by Andrejco, Lowrance, Morgan, Padgett, and Collins, social media utilizing podcasts were explored as a reproducible method in the education of Nurse Anesthetists (2017). The Logic Model was applied to following goals: creation of an educational podcast for the anesthesia community; development of a website to serve as a hub where listeners can connect to find podcast; and publishing of a paper in $A A N A$ Journal to outline a reproducible model for an educational podcast. Podcasts were created after conducting a review of the literature, recording willing providers, and editing the podcasts to a newly created website for distribution. The Logic Model was used to logically link specific resources, actions, and outputs to the program's desired 
outcomes of a reproducible model used for creating and developing educational podcasts and websites by educators for nurses (Andrejco et al.).

The second model utilized is the Synergy Model for Patient Care (Curley, 1998; Figure 2). The Synergy Model is based on using the unique characteristics of both the patient/family and nurse to create a dynamic relationship in order to provide a unique plan of care tailored to the individual. These characteristics or needs of the patient/family drive the competencies of the nurses that provide care for them.

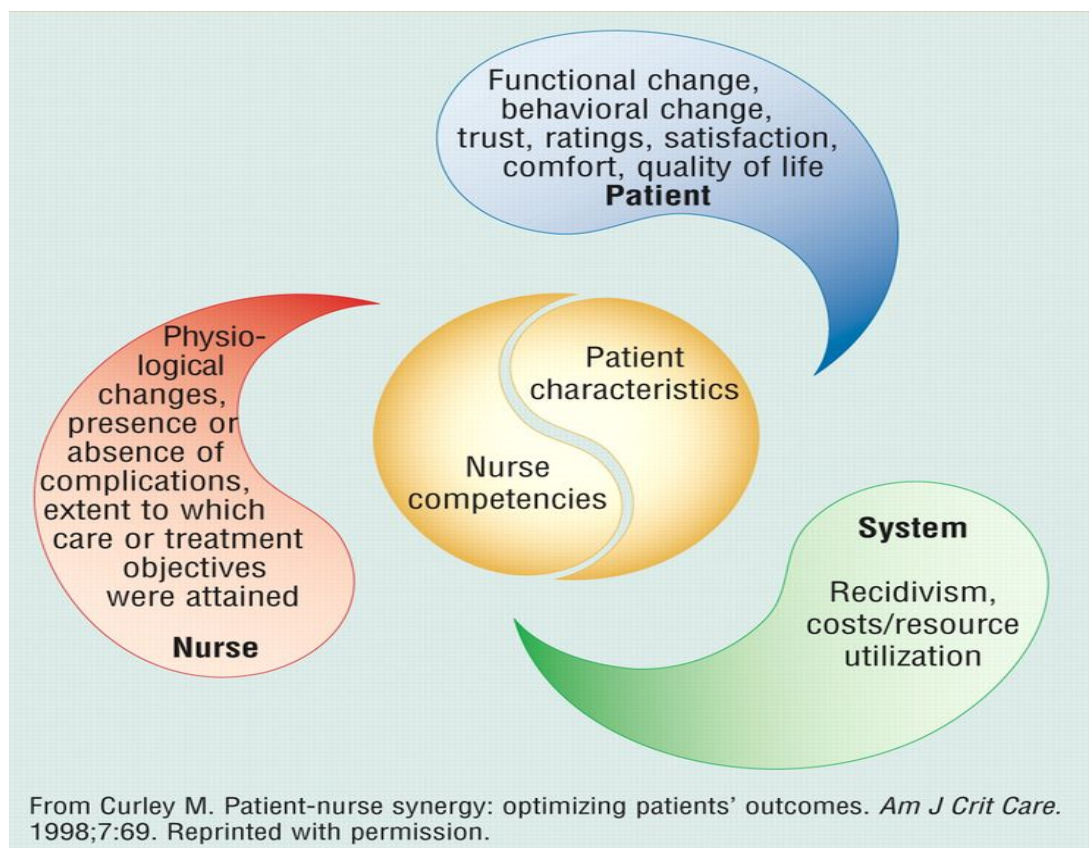

Figure 2. The Synergy Model. Curley, 1998.

Patients are not described by a single characteristic, but rather by eight individual characteristics that are connected and that contribute to a whole individual. These are resiliency, vulnerability, stability, complexity, resource availability, participation in care, participation in decision making, and predictability. A lack of stability, the ability to maintain steady state equilibrium (AACN, 2011), can equate to changes in neurological 
status, pain/comfort management, or a lack of family's support that impact the patient (Kohr, Hickey, \& Curley, 2012). Predictability is a characteristic that allows certain expectations during a course of events or course of illness (AACN). This can mean, for the patient, a change in the direction of illness or a complex social history/history of family response and coping (Kohr et al., 2012). Vulnerability is the susceptibility to actual or potential stressors that could affect patient outcomes in an adverse manner (AACN) such as a prolonged length of stay, poor socioeconomic status, the inability of family to be involved in care (Kohr et al.). Complexity is the intricate involvement of two or more systems (AACN) and can result in difficulty in meeting discharge requirements (Kohr et al.). Resiliency is the capacity to return to a restorative level of functioning using compensatory/coping mechanisms to bounce back quickly after an insult (AACN). Nutritional status, family availability/ support/understanding, effective/ineffective family capacity to cope, and individual poor coping mechanisms can all negatively impact a patient's resiliency (Kohr et al.). Patient and/or family participation in decision making and care which is the extent to which patient/family engages in aspects of care or the resources (e.g., technical, fiscal, personal, psychological, and social) the patient/family/community bring to the situation (AACN). This can encompass family dynamics (or the lack of family), length of stay, the available resources, patient/family variables as well as hospital variables (Kohr et al.).

Nursing competencies consist of clinical judgement, clinical inquiry, caring practices, response to diversity, advocacy/moral agency, facilitation of learning, collaboration, and systems thinking. Clinical judgement, or clinical reasoning, is clinical decision-making and critical thinking (AACN, 2011). Clinical inquiry involves the 
ongoing process of continually reevaluating practice to inform best practice (AACN). Caring practices are nursing activities that help to mold a compassionate, supportive, and therapeutic environment for both patients and staff (AACN). Response to diversity includes the sensitivity to recognize, appreciate and incorporate differences into the care provided to the patient (AACN). Advocacy/moral agency is working on another's behalf and representing the concerns of the patient/family as well as nursing staff to identify and help resolve ethical and clinical concerns (AACN). Facilitation of learning is the ability to facilitate learning for patients/families, nursing staff, other members of the healthcare team and community (AACN). In its' simplest definition, collaboration is working with others. Collaboration in the synergy model involves working with others towards optimal/realistic patient/family goals (AACN). Systems thinking involves a body of knowledge and tools used to navigate resources for patient/family and staff (AACN).

The goal of this quality improvement project is to align the needs of the adult inpatient diabetic population with the nurse competencies required to achieve optimal outcomes for the patient, nurse, and system (Alspach, 2006). Diabetes is a chronic health condition that would benefit from utilizing both the systematic approach of the Logic Model and a tailored model to meet patient/family needs such as the Synergy Model. The Logic Model can be used to create a reproducible method of education that also can effectively measure and capture desired outcomes while the synergy model considers the individuality of every nurse and patient.

The methodology guiding this quality improvement project will be discussed next. 


\section{Method}

\section{Purpose}

The purpose of this quality improvement project was to determine whether the implementation of a diabetic education program improves nurses' knowledge in the medical management, treatment, and care of the adult critical care patient with hyperglycemia

\section{Design}

This quality improvement project used a pre-test, post-test design to determine whether nurses' knowledge of the adult inpatient with diabetes is improved with a diabetes education program.

\section{Site}

The project was conducted on the Special Care Unit (SCU) at The Miriam Hospital, a 247-bed, not-for-profit, community teaching hospital that provides a broad range of primary, secondary and tertiary medical services to adolescents and adults in 34 medical and surgical specialties and subspecialties. The SCU is a 20-bed unit that cares for intermediate care, medical-surgical and bariatric surgery patients.

\section{Sample}

A convenience sample of critical care registered nurses (RNs) providing inpatient care to patients on the SCU was used $(\mathrm{N}=36)$. Inclusion criteria consisted of current registered nurses in the SCU that provide direct patient care. Exclusion criteria included non-SCU nurses, travel nurses, and float pool staff. 


\section{Procedures}

This quality improvement project followed the Logic Model using input, activities, output, outcomes, and impact to guide the research process (W. K. Kellogg Foundation, 2004).

Input. A needs assessment, performed by the Clinical Manager (CM), Assistant Clinical Manager (ACM) and Advanced Practice Manager (APM) identified knowledge needs of the SCU nurses related to hyperglycemia in the critically ill patient. Based on this assessment, appropriate testing and educational materials were prepared to meet identified educational needs of SCU nurses. After approval of nursing leadership, the proposal was submitted to Lifespan Institutional Review Board (IRB) which determined that this quality improvement project was not research, followed by a not research determination by the Rhode Island College IRB.

Activities. The activities consisted of the pre-test, educational session, and posttest. After IRB determination, recruitment began for the educational sessions. Recruitment included an informational email (Appendix A) to RNs in the SCU approximately 3 weeks prior and flyers (Appendix B) posted approximately 2 weeks prior to the start of the education sessions. Unit leadership encouraged staff participation through direct communication during daily huddles as well as providing unit patient care coverage during educational sessions. Additionally, the CM suggested the times of the education that were convenient for the staff. The only recruitment incentive offered were light refreshments at each educational session. Participation was voluntary and participants could decline participation at any time during the educational session. 
All educational sessions were completed within a two-week period. The objectives of the 20-minute educational program were that the learner would be able to: (1) describe the pathophysiology differences between diabetes types I and II, (2) state the differences between hyperglycemia, Diabetic Ketoacidosis (DKA), and Hyperosmolar Hyperglycemic State (HHS), (3) explain how to calculate an anion gap, (4) describe the possible outcomes and treatments related to a wide gap, and (5) List common lab findings in hyperglycemic conditions (Appendix C). The pre-test/post-test sought to measure the education program objectives (Appendix D). The pre-test was completed prior to the educational intervention, and the post-test at the end of each educational program session. After a brief introduction and review of educational objectives, the pencil and paper pretest was administered to all participants to determine baseline knowledge. The pre-test included an additional question asking years of experience ( $<2$ years, $>2-6$ years, $>6-10$ years, and $>10$ years). Each $\mathrm{RN}$ was instructed to write an identical, easily remembered four-digit code on both the pre- and post-test as an identifier in order to compare individual as well as aggregate scores. After collection of the pre-test, the 15 to 20minute face to face educational session was presented. Six educational sessions were offered over a two-week period. Two were conducted prior to the start of day-shift (0630) and two after night shift turnover (0730) to make the session available and convenient for all shifts. Two additional sessions were offered at 1430 as added opportunities for staff nurses to attend. Completed post-tests with four-digit code were collected after each educational session and stored in a locked office.

Output. The output is comprised of the measured scores of the pre- and posttests. The outcome measures are the comparison of measured scores between pre-test 
before and post-tests after educational intervention. Pre- and post-test scores were compiled and summarized using descriptive statistical analysis. The mean was determined of both the pre-test and post-test scores. Pre-test scores were analyzed by years of experience to determine any correlation between experience and baseline knowledge. Comparison of pre-test and post-test scores individually and in the aggregate were used to determine the effectiveness of the educational session.

Impact. The overall desired impact was increased inpatient nursing knowledge demonstrated by improved post-education test scores, generalizable to other inpatient units that care for the adult diabetic population. Quality improvement outcomes/data was presented to staff on the participating unit and management forums.

\section{Measurement}

A 10-question pre/post-test was used to measure the effectiveness of the educational session. Due to the limitations of current diabetes knowledge tests, the educational intervention, pre and post-test for this quality improvement project was derived from evidence-based literature, continuing education content by Brenner (2006) and Sanuck, Bidlencik \& Volk (2014). The test was reviewed by three APM content experts from $\mathrm{TMH}$.

\section{Challenges and Opportunities}

Institutional resources include unit and nursing leadership support for this project. The Miriam Hospital is a Magnet designated facility, and supports staff engagement in 
educational opportunities. Anticipated challenges included unit needs preventing SCU nurses' attendance and participation in educational sessions. Another anticipated challenge was the possible inability to complete the educational session and pre/post-tests within the 30-minute time-limit, leading to incomplete data collection. Patient care is the priority, and individual completion of the program could potentially be impacted by unanticipated events. Management was available to assist as needed to ensure a safe patient environment during the scheduled educational sessions.

Alternate educational opportunities available to nurses such as current enrollment in a master's/doctorate level nursing program, journal articles, or other diabetes education activities may affect an individual's diabetes knowledge. Finally, the creation of a new test rather than using a previously studied test may be a limiting factor. A new test was created due to the lack of higher-level tests available. Nurses perceived knowledge of diabetes was not included in this project.

\section{Ethical Considerations}

The study was reviewed through both the Lifespan Institutional Review Board (IRB) for determination as a quality improvement project as well as the Rhode Island College IRB. Participants were informed that agreement to participate is voluntary and qualified as consent. Participants were also aware that they could withdraw at any time, for any reason, without penalty. No personally identifying information was collected, and tests remained anonymous. Managers encouraged nurses attendance, but they were not aware of who attended the educational sessions. 


\section{Dissemination}

Findings were analyzed using descriptive statistical analysis and presented in graph form to depict outcomes of the educational intervention based on mean scores of the pre- and post-test. Results were disseminated to the inpatient management as well as the SCU nursing staff. This educational program has applicability to other nursing areas where care is delivered to diabetic patients. The Miriam nursing staff had previously identified diabetes as a nursing education need. The program materials and results of this project were disseminated to the education team responsible for the planning and implementation of an upcoming diabetes education project for implementation in the development of an education program for all nurses throughout the hospital to include critical care areas as well as general inpatient care areas. These findings were additionally disseminated in May at Rhode Island College as a poster presentation.

Next, the results will be discussed. 


\section{Results}

A total of twenty-one nurses attended 6 educational sessions. Two nurses who participated in the program did not meet inclusion criteria and two nurses who met inclusion criteria attended the educational session but did not take the pre-test and posttest. Seventeen of a possible 36 nurses completed the pre-test, educational session, and post-test $(\mathrm{n}=17 ; 47.2 \%)$. The pre-test and post-test consisted of 10 questions. Each question had a single correct response. Answers that were left unanswered or had multiple responses selected were counted as incorrect. The pre-test scores and post-test scores showed a $29.4 \%$ increase in overall correct answers from pre-test (54.7\%) to posttest scores $(84.1 \%)$.

The pre-test and post-test scores were evaluated by the mean scores of each pretest and post-test question individually (Figure 3). Eight out of 10 questions showed improvement after educational intervention. These 10 questions fell into one of the three categories: pathophysiology, diabetes management, or treatment of hyperglycemic states.

The greatest overall improvement in knowledge gained with educational intervention was achieved in the area of diabetes management (0.51). Three of the questions covered nursing management of diabetes (2, 4, and 5). Question 2 which asks about HHS findings showed an increase of 35.5\% to 70.6\% (+35.3\%). Question 4, which asked to identify the four major lab findings in DKA and HSS had the most significant improvement, with a pre-test score of $35.3 \%$ and a post-test score of $100 \%$, an increase of 64.7\% after educational intervention. Question 5 asks the major clinical feature of HHS and resulted in pre-test scores of $41.1 \%$ and post-test scores of $94.1 \%(+53 \%)$. 
The next best improvement was attained in the knowledge of the treatment of hyperglycemic states $(0.255)$, questions 3,9 , and 10 . Question 3 refers to the criteria for DKA resolution and resulted in pre-test correct answers $70.6 \%$ and post-test answers 94.1\% (+23.5\%). Question 9 asks about the differences in lab values between DKA and HHS. This resulted in no change between pre-test and post-test scores of $70.6 \%$. Question 10 refers to the measures used to calculate the anion gap. This also showed an improvement in pre-test scores of $47.0 \%$ to post-test scores of $100 \%$, resulting in a $53 \%$ increase.

Pathophysiology showed the least amount of overall improvement between pretest and post-test scores (0.205), questions 1, 6, 7, and 8. Staff base knowledge of pathophysiology had wide variability across the four questions as well as variability in knowledge after the education program. Question 1 which asks about the characteristics of DKA showed a slight increase from a pre-test score of $35.3 \%$ to $41.1 \%(+5.8 \%)$. Question 6 refers to the definition of ketosis and resulted in a pre-test score of $76.5 \%$ and a post-test of $88.2 \%(+11.7 \%)$. Question 7 asks about the primary risk factor for type 1 diabetes, and had a pre-test score of $35.3 \%$ to a post-test mean of $94.1 \%$. This showed a $58.8 \%$ increase in scores after educational intervention. Question 8 which asked the primary risk factor for type 2 diabetes had a pre-test score of $100 \%$, with one person incorrectly answering the question after educational intervention (-5.9\%). 


\begin{tabular}{|c|c|c|}
\hline Question & Pre-Test & Post-Test \\
\hline 1 & $6(35.3 \%)$ & $7(41.1 \%)$ \\
\hline 2 & $6(35.3 \%)$ & $12(70.6 \%)$ \\
\hline 3 & $12(70.6 \%)$ & $16(94.1 \%)$ \\
\hline 4 & $6(35.3 \%)$ & $17(100 \%)$ \\
\hline 5 & $7(41.1 \%)$ & $16(88.2 \%)$ \\
\hline 6 & $13(76.5 \%)$ & $16(94.1 \%)$ \\
\hline 7 & $6(35.3 \%)$ & $16(94.1 \%)$ \\
\hline 8 & $17(100 \%)$ & $17(70.6 \%)$ \\
\hline 9 & $12(70.6 \%)$ & $100 \%)$ \\
\hline 10 & $8(47.0 \%)$ & \\
\hline
\end{tabular}

Figure 3: Mean Individual Test Question Scores

Improvement in all three areas demonstrated that this educational intervention was effective in improving nurse's knowledge in the pathophysiology of diabetes, medical management, treatment, and care of the adult critical care patient with hyperglycemia. 


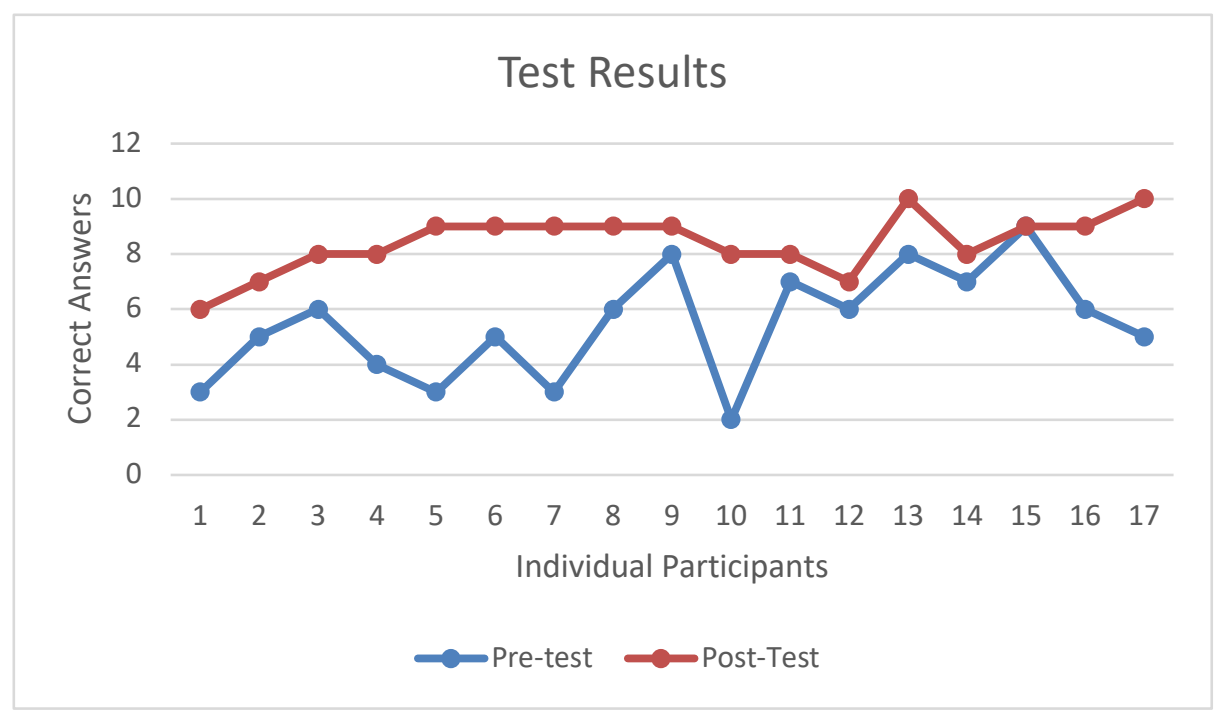

Figure 4. Individual Participant Pre-test and Post-test

Individual participant pre-test and post-test scores are depicted in graph form in

Figure 4. Sixteen out of 17 individual participant test scores improved after the educational intervention. While one individual score remained unchanged between pretest and post-test score (90\%), 3 individuals improved $60 \%$ between pre-test and post-test scores. One individual improved 50\%, 2 improved 40\%, and the remaining 10 individuals improved 10-30\% between pre-test and post-test scores.

All participants were asked to voluntarily provide their years of nursing experience. This was identified as the number of years they had actively held a nursing license and broken into the categories of $<2$ years, $>2-6$ years, $>6-10$ years, and $>10$ years (Figure 5). While the $>2-6$-year experience group gained the most significant overall mean test score improvement, the $<2$-year experience group resulted in the highest overall pre-test and post-test scores. The nurses with $<2$ years' experience $(n=7)$ began with a mean pre-test score of $62.8 \%$, improving to $88.5 \%$ after educational intervention, a $25.7 \%$ overall increase. The $>2-6$-year experience group $(n=5)$ began with a mean pre- 
test score of $50 \%$ to a post-test mean of $86 \%$, resulting in the most significant increase in scores $(36 \%)$. The $>6-10$-year experience group $(n=3)$ began with a mean pre-test score of $43 \%$ increasing to a post-test mean of $76.6 \%$, a $33.6 \%$ overall increase. The $>10$-year experience group $(n=2)$ began with a mean pre-test score of $55 \%$ and increased to a mean post-test score of $75 \%$, a $20 \%$ overall increase.

\begin{tabular}{|c|c|c|c|}
\hline Years' Experience & Pre-test & Post-test & \% Change \\
\hline$<2$ years $(\mathrm{n}=7)$ & 62.8 & 88.5 & $25.7+$ \\
\hline$>2-6$ years $(\mathrm{n}=5)$ & 50.0 & 86.0 & $36+$ \\
\hline$>6-10$ years $(\mathrm{n}=3)$ & 43.0 & 76.6 & $33.6+$ \\
\hline$>10$ years $(\mathrm{n}=2)$ & 55.0 & 75.0 & $20+$ \\
\hline
\end{tabular}

Figure 5. Mean Scores by Years' Experience

Next, the summary and conclusions will be discussed. 


\section{Summary and Conclusions}

The incidence of hyperglycemia in the critically ill population is much higher than in the general medical population. At least 50\% of Intensive Care Unit (ICU) patients experience hyperglycemia (Faust, Attridge, \& Ryan, 2011). These elevated blood glucose concentrations are known to be associated with adverse outcomes (Faust et al., 2011).

Diabetes is a disease where hyperglycemia results from an improperly functioning pancreas resulting in an absence of insufficiency of insulin within the body. Diabetic ketoacidosis, is a state of insulin deficiency combined with an increase of insulinantagonistic hormones resulting in the altered metabolism of carbohydrates, fats, and proteins. Excess glucose production occurs, as does an increase in the synthesis of ketones and lactic acidosis resulting in ketosis and metabolic acidosis. The hallmark clinical finding of DKA is the combination of hyperglycemia, a low serum bicarbonate, and an elevated anion gap (Sanuth, Bidlencik \& Volk, 2014). Hyperosmolar hyperglycemic state is a life-threatening hyperglycemic emergency due to insufficient insulin. Impaired glucose transport across the cell membrane results, and fluid shifts from intracellular to extracellular spaces to offset this. Fluid deficits and electrolyte losses are much more severe than in DKA (Sanuth, Bidlenicik \& Volk, 2014).

Nurses at the bedside are integral to the effective management, treatment, and care of the critically ill adult diabetic patient experiencing hyperglycemia. Nurses' comprehensive knowledge of the pathophysiology of diabetes is required to provide quality, safe care to the critical care patient population. Trepp, Wille, Wieland, and Reinhart (2010) found that when questioned about topics beyond the basics of diabetes, 
$43 \%$ of nurses demonstrated low scores. Modic, Vanderbilt, Siedlecki, Sauvey, Kaser, and Yager (2014) demonstrated increased test scores $(\mathrm{x}=11, \mathrm{x}=20)$ after a four-hour educational intervention and demonstrated that nurses were not current in diabetes inpatient care. Wakefield and Wilson (2014) also showed an increased in mean raw scores $(35 \%)$ with educational intervention and noting poor pre-education scores in the application of knowledge related to diabetes.

This quality improvement project was developed for the SCU. Coincidentally, nurses throughout The Miriam Hospital (TMH) had identified the need for and requested education on diabetes care. The educational intervention was created based upon topics identified by SCU nursing management, of particular need is increased knowledge of anion gap and DKA management. The educational intervention effectiveness was measured using a pre-test/post-test method. Pre-test/post-test questions were derived from the educational program objectives and content, validated by local content experts. An additional question was included to determine years of nursing experience. The pretest was administered, followed by the educational intervention, and post-test administration in six separate sessions. Each session took no more than 30 minutes to complete.

Seventeen of a possible 36 nurses completed an entire session. Scores increased from a mean pre-test score of $54.7 \%$ to a post-test mean of $84.1 \%$. This demonstrates an improvement of $29.4 \%$ in overall scores. Eight out of 10 questions had improved posttest scores after educational intervention, with the exception that question 8 had a slight decreased score (17/17 to $16 / 17)$ and question 9 showing no improvement (12/17 to 12/17). Question 4 regarding laboratory findings in DKA and HHS showed the most 
significant improvement after educational intervention (pre-test $6 / 17$ to post-test 17/17), a $64.7 \%$ increase in scores. Additionally, scores were categorized into four groups based on nursing experience; $<2$ years, $>2-6$ years, $>6-10$ years, and $>10$ years. Nurses with $>2-6$ years' experience showed the most improvement with educational intervention (36\%), followed by $>6-10(33.6 \%),<2$ years $(25.7 \%)$, and finally $>10$ years $(20 \%)$. Nurses with $<2$ years' experience demonstrated the highest overall pre-test and post-test scores.

The purpose of this quality improvement project was to determine whether the implementation of a diabetic education program improves nurses' knowledge in the medical management, treatment, and care of the adult critical care patient with hyperglycemia. The variability in baseline knowledge and overall significant improvement in scores validated the need for this program and may indicate a need to focus future educational programs on the care of the patient with diabetes.

\section{Limitations}

Educational sessions were offered either before or after each shift to accommodate all staff members. However, times may still have not been optimal. Those completing the session at or near the end of the night shift (0630 and 0730) expressed the desire to have the sessions offered instead at 1830 and 1930. Many nurses completing the session after night shift stated they were very tired after their shift, so their session may have more optimal if it had been offered prior to the start of night shift. Offering additional sessions during scheduled work time may also have contributed to a higher rate of participation. 
Management was supportive in covering patient needs during the educational session. However, nurses were still occasionally distracted by questions about their patients. Anecdotally, these nurses also reported that they were appreciative to have the session offered during their shift, so additional time was not required.

The testing requirement resulted in one nurse choosing to attend only a portion of the educational session and decline participation in the test. Another nurse was able to only attend the educational session due to patient care needs and was not scheduled to work during the other offerings. Of note, two non-SCU nurses attended only the educational session due to interest in the presentation topic. Additionally, due to the small number of participants for the project, the validity of the results obtained from this project may be decreased. A larger number of participants would be recommended for future projects of similar interest in order to validate the positive test score results gained from this project.

Next, the recommendations and implications for advanced nursing practice will be discussed. 


\section{Recommendations and Implications for Advanced Nursing Practice}

This facility clearly identified the need and desire for education on the care of the diabetic inpatient prior to the start of this quality improvement project. Literature review findings suggest a gap in the knowledge of nurses caring for the inpatient diabetic with minimal research conducted in the area of critical care. The literature also supports educational interventions as an effective method of improving overall knowledge of the inpatient nurse providing diabetes management, treatment, and care. The APRN plays an integral role in identifying these gaps and devising the best method for resolution of the differences between the literature and practice at the bedside.

After completion of this quality improvement project, the request was made for the information presented within this quality improvement project to be made available to management for dissemination to all SCU nurses. The APM of the unit will be providing the educational session to staff who did not participate during this quality improvement project to ensure $100 \%$ participation of the unit. Additionally, since the request for diabetes education came from throughout the facility, the material was requested to be utilized by the Quality Practice Council for hospital-wide education. Management from SCU also requested to use the material in order to create a binder for staff to reference in caring for the inpatient diabetic population. Interest on the topic was piqued, and a follow up 6-month education retention administration of the 10-question test to the SCU nursing staff is currently being considered.

These requests from the facility, future plans for dissemination and education, as well as the results from this quality improvement project demonstrate a clear need for further education on hyperglycemia in the critical care environment. 


\section{References}

Alotaibi, A., Gholizadeh, L., Al-Ganmi, A., \& Perry, L. (2017). Examining perceived and actual diabetes knowledge among nurses working in a tertiary hospital. Applied Nursing Research, 35, 24-29.

Alspach, J. (2006). Core Curriculum for Critical Care Nursing. Elsevier Health Sciences.

American Association of Clinical Endocrinologists. (2018). AACE Diabetes Resource Center. Retrieved from: http://inpatient.aace.com/rationale-for-achievingglycemic-control.

American Association of Critical-Care Nurses, \& American Association of Critical-Care Nurses. (2011). The AACN synergy model for patient care.

American Association of Diabetes Educators. (2017). AADE7 Self Care Behaviors. Retrieved from: https://www.diabeteseducator.org/patient-resources/aade7-selfcare-behaviors.

American Diabetes Association. (2018). Statistics About Diabetes. Retrieved from: http://www.diabetes.org/diabetes-basics/statistics/.

American Diabetes Association. (2018). Standards of medical care in diabetes-2018. Diabetes care, 41(Supplement 1), S1-S159.

Andrejco, K., Lowrance, J., Morgan, B., Padgett, C., Collins, S. (2017). Social Media in Nurse Anesthesia: A Model of a Reproducible Educational Podcast. AANA Journal, 85(1). 
Brenner, Z. R. (2006). Management of hyperglycemic emergencies. AACN advanced critical care, 17(1), 56-65.

CDC. (2009). Logic Models for Planning and Evaluation. Retrieved from: https://www.cdc.gov/ncbddd/birthdefects/models/resource1evaluationguide2009.pdf.

Childers, B., \& Levesque, C. (2013). Use of Insulin in the Noncritically Ill-Hospitalized Patients with Hyperglycemia and Diabetes. Critical Care Nursing Clinics, 25(1), $55-70$.

Collins, G., Mughal, S., Barnett, A., Fitzgerald, J., \& Lloyd, C. (2011). Modification and validation of the revised diabetes knowledge scale. Diabetic Medicine, 28(3), 306-310.

Curley, M. A. (1998). Patient-nurse synergy: optimizing patients' outcomes. American Journal of Critical Care, 7(1), 64.

DeJesus, R., Breitkopf, C., Rutten, L., Jacobson, D., Wilson, P., \& Sauver, J. (2017). Incidence rate of prediabetes progression to diabetes: modeling an optimum target group for intervention. Population health management, 20(3), 216-223.

Etzwiler, D. (1967). Who's teaching the diabetic?. Diabetes, 16(2), 111-117.

Faust, A., Attridge, R., \& Ryan, L. (2011). How low should you go? The limbo of glycemic control in intensive care units. Critical care nurse, 31(4), e9-e18. 
Fitzgerald, J., Funnell, M., Anderson, R., Nwankwo, R., Stansfield, R., \& Piatt, G. (2016). Validation of the revised brief Diabetes Knowledge Test (DKT2). The Diabetes Educator, 42(2), 178-187.

Francisco, M. (2013). Instruments that measure nurses' knowledge about diabetes: An integrative review. Journal of nursing measurement, 21(1), 137-152.

Freeland, B. (2016). Hyperglycemia in the hospital setting. MedSurg Nursing, 25(6), 393397.

Grossman, S., Porth, C. (2014). Porth's pathophysiology: Concepts of altered health states. Porth's pathophysiology: concepts of altered health states. Philadelphia: Wolters Kluwer Health/Lippincott Williams \& Wilkins.

Kohr, L., Hickey, P., \& Curley, M. (2012). Building a nursing productivity measure based on the synergy model: First steps. American Journal of Critical Care, 21(6), 420-431.

Jivanji, C., Asrani, V., Windsor, J., \& Petrov, M. (2017, May). New-onset diabetes after acute and critical illness: a systematic review. In Mayo Clinic Proceedings (Vol. 92, No. 5, pp. 762-773). Elsevier.

Keaveny, J. (2013). Critical Care Diabetes Education. Critical Care Nursing Clinics, 25(1), 123-130.

Lee, P., \& Halter, J. (2017). The pathophysiology of hyperglycemia in older adults: clinical considerations. Diabetes care, 40(4), 444-452. 
Michigan Diabetes Research Center (MDRC). (2017). Tools for Health Professionals. Retrieved from: http://diabetesresearch.med.umich.edu/Tools_SurveyInstruments.php.

Moattari, M., Moosavinasab, E., Dabbaghmanesh, M., \& ZarifSanaiey, N. (2014). Validating a Web-based Diabetes Education Program in continuing nursing education: knowledge and competency change and user perceptions on usability and quality. Journal of Diabetes \& Metabolic Disorders, 13(1), 70.

Modic, M., Vanderbilt, A., Siedlecki, S., Sauvey, R., Kaser, N., \& Yager, C. (2014). Diabetes management unawareness: what do bedside nurses know? Applied Nursing Research, 27(3), 157-161.

Morzinski, J., \& Montagnini, M. (2002). Logic modeling: A tool for improving educational programs. Journal of Palliative Medicine, 5(4), 566-570.

Paquette-Warren, J., Roberts, S., Fournie, M., Tyler, M., Brown, J., \& Harris, S. (2014). Improving chronic care through continuing education of interprofessional primary healthcare teams: A process evaluation. Journal of interprofessional care, 28(3), 232-238.

Sanuth, B., Bidlencik, A., \& Volk, A. (2014). Management of acute hyperglycemic emergencies: Focus on diabetic ketoacidosis. AACN advanced critical care, 25(3), 197-202.

Scheiderich, S., FreiBaum, C., \& Peterson, L. (1983). Registered nurses' knowledge about diabetes mellitus. Diabetes Care, 6(1), 57-61. 
Trepp, R., Wille, T., Wieland, T., \& Reinhart, W. (2010). Diabetes-related knowledge among medical and nursing house staff. Swiss medical weekly, 140(25), 370.

Umpierrez, G., Hellman, R., Korytkowski, M., Kosiborod, M., Maynard, G., Montori, V., ... \& Van den Berghe, G. (2012). Management of hyperglycemia in hospitalized patients in non-critical care setting: an endocrine society clinical practice guideline. The Journal of Clinical Endocrinology \& Metabolism, 97(1), 16-38.

Van Melle, E. (2016). Using a logic model to assist in the planning, implementation, and evaluation of educational programs. Academic Medicine, 91(10), 1464.

Wakefield, P., \& Wilson, M. (2014). Enhancing Nurses' Knowledge Regarding the Complex Care of Hospitalized Patients on Insulin. Journal for nurses in professional development, 30(4), 174-180.

W. K. Kellogg Foundation. (2004). W.K. Kellogg Foundation Logic Model development guide. Retrieved from: https://www.wkkf.org/resourcedirectory/resource/2006/02/wk-kellogg-foundation-logic-model-developmentguide. 
Appendix A

\section{Informational Letter}

\section{Diabetes Knowledge of Critical Care Nurses: A Quality Improvement Project}

Special Care Unit Nurses,

Sarah Huley, a Clinical Nurse Specialist student in the Masters Nursing Program

at Rhode Island College, along with the Principal Investigator, Kara Misto, is completing a quality improvement project in the SCU as part of her Master's program. The purpose of this quality improvement project is to determine whether the implementation of a diabetic education program improves nurses' knowledge in the medical management, treatment, and care of the adult critical care patient with hyperglycemia. In order to complete this quality improvement project, you are being asked to participate.

Participation is voluntary and if you agree to participate, it will involve the completion of an anonymous pre-test, a 15-20-minute educational session, and completion of a posttest. The total time to complete this activity will be approximately 30 minutes. The goal of this project is to improve nurses' knowledge in the medical management, treatment, and care of the adult critical care patient with hyperglycemia.

The pre-/post-test will consist of 10 questions with the additional request to select a category of your number of years nursing experience. The test questions are aimed at diabetes knowledge, and should not cause any level of discomfort. Participation in the pre-/post-test is voluntary and you may withdraw at any time. No personal information will be collected, a unique four-digit code determined by the individual participant will be used to correlate pre- and post-test completion. 
If you have any questions or concerns regarding the project, you may contact me at (608)-346-0592 or shuley_0418@email.ric.edu. You may also contact Patricia Calvert, the major advisor of this project at (401)-456-6323 or pcalvert@ric.edu or Dr. Kara Misto at (401-456-8013 or kmisto@,ric.edu. I look forward to working with the nurses of SCU and hope you will consider participation in this quality improvement project.

Thank you, Sarah Huley 
Appendix B

\section{$\underline{\text { SCU Nurses Needed }}$}

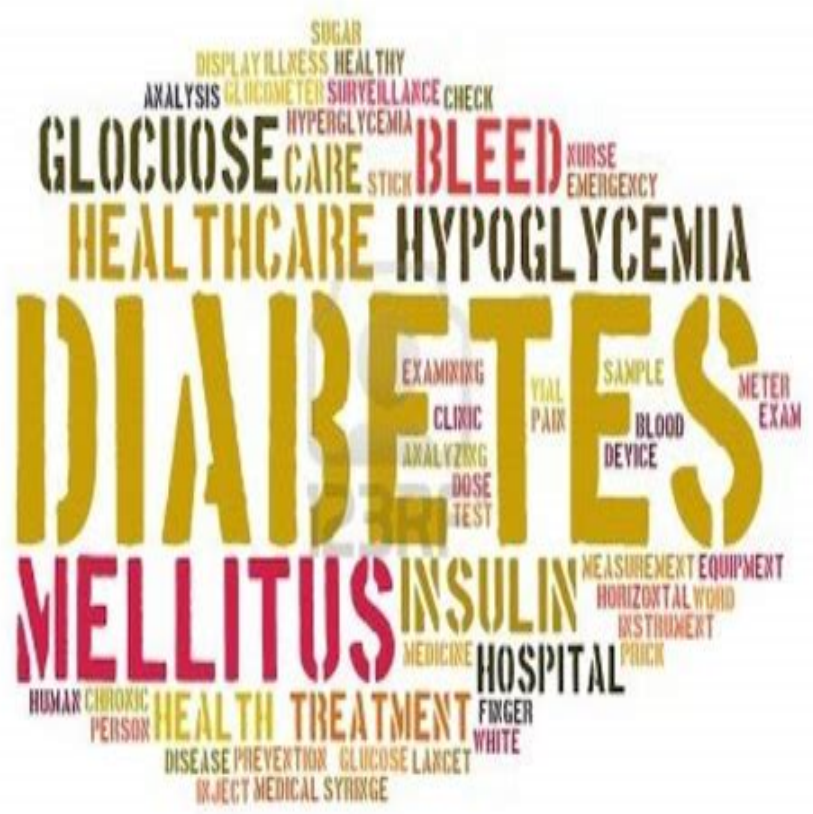

I am looking for registered nurses to participate in a quality improvement project.

This project will include:

-10 question pre-test

-15-20-minute education session on the pathophysiology, management, and treatment of hyperglycemic states.

-10 question post-test

Who: SCU Registered Nurses

What: Diabetes Knowledge of Critical Care Nurses: A Quality Improvement Project

\section{Objectives:}

1. Describe the pathophysiology differences between diabetes types I and II.

2. State the differences between hyperglycemia, Diabetic Ketoacidosis (DKA), and

Hyperosmolar Hyperglycemic State (HHS).

3. Explain how to calculate an anion gap.

4. Describe possible outcomes and treatments related to a wide gap.

5. List common lab findings in hyperglycemic conditions.

Where: SCU break room

When: December $3^{\text {rd }}$ and $5^{\text {th }}$ at 0630 and 0730; December $12^{\text {th }}$ and $13^{\text {th }}$ at 1430

Contact: Sarah Huley (608) 346-0592 or shuley_0418@email.ric.edu

Dr. Kara Misto (Principal Investigator)

Rhode Island College 
Appendix C
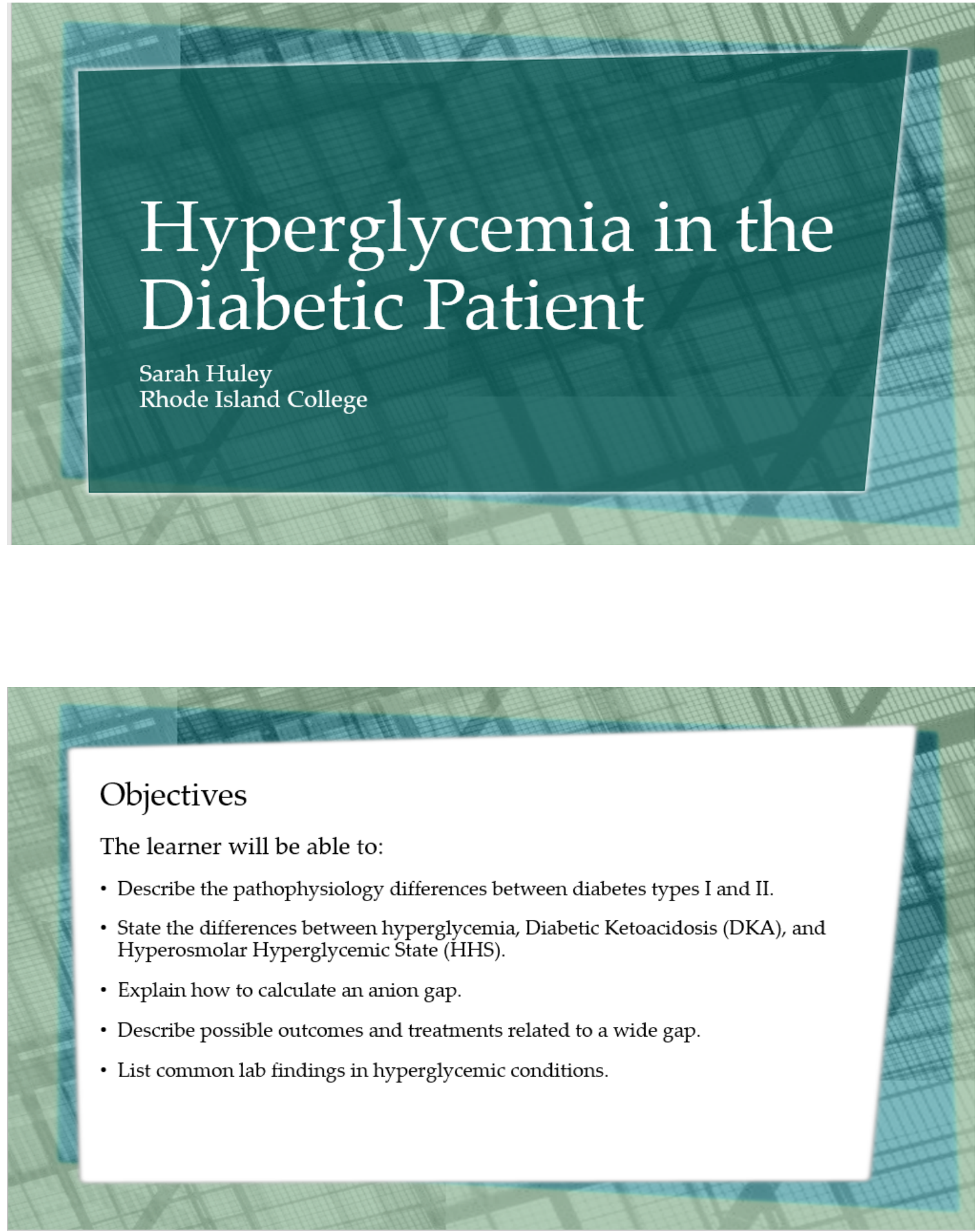

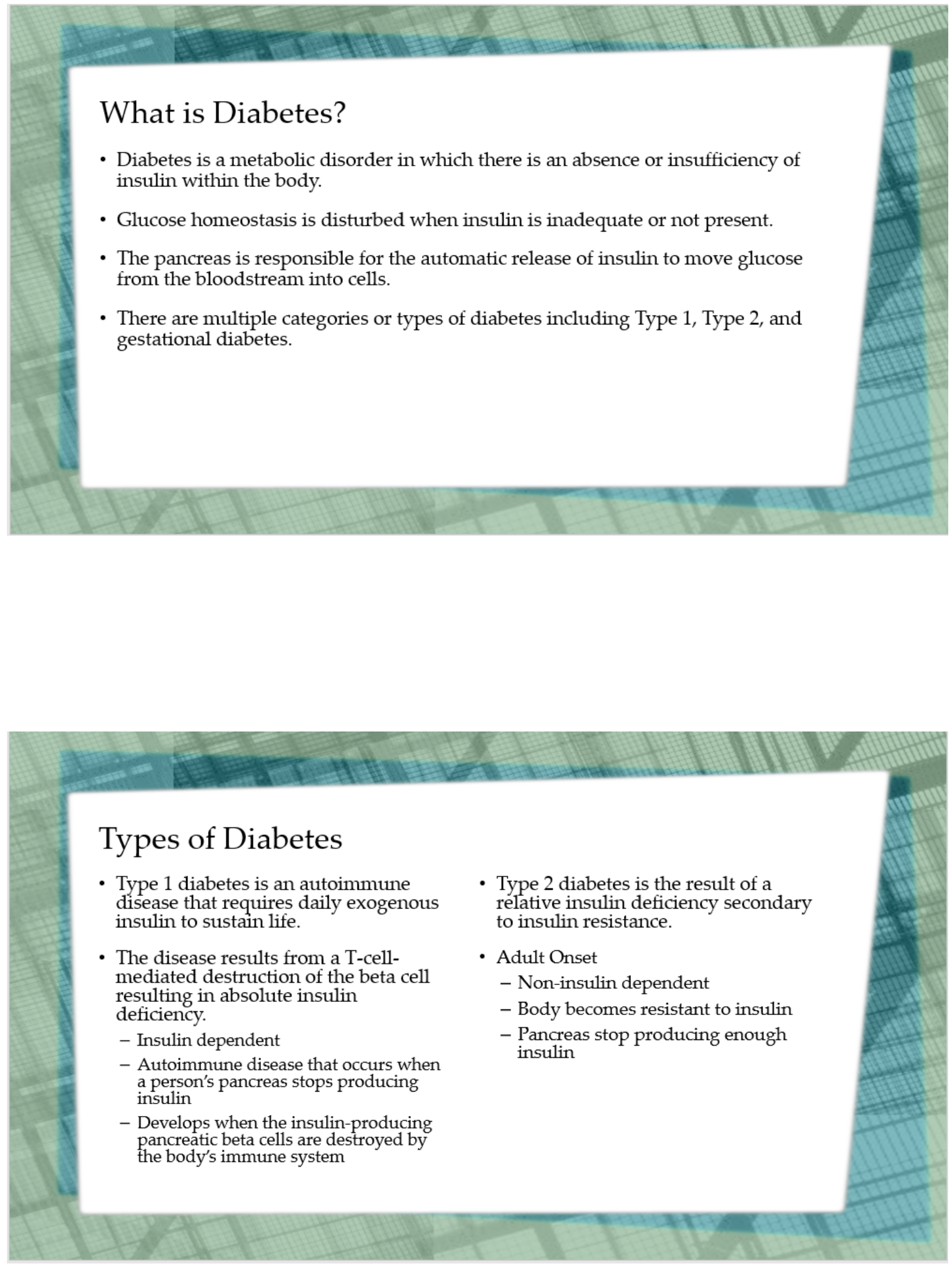

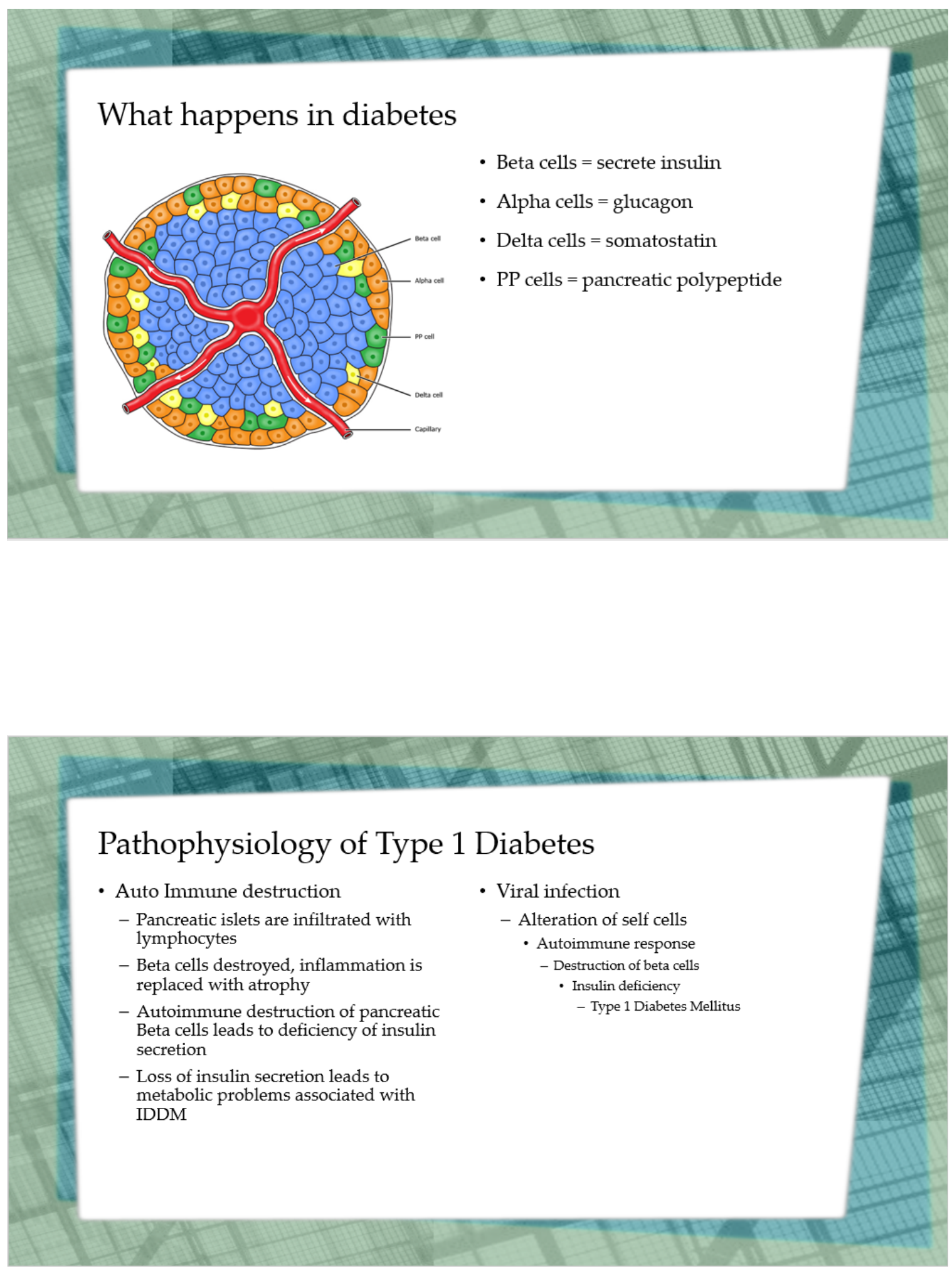

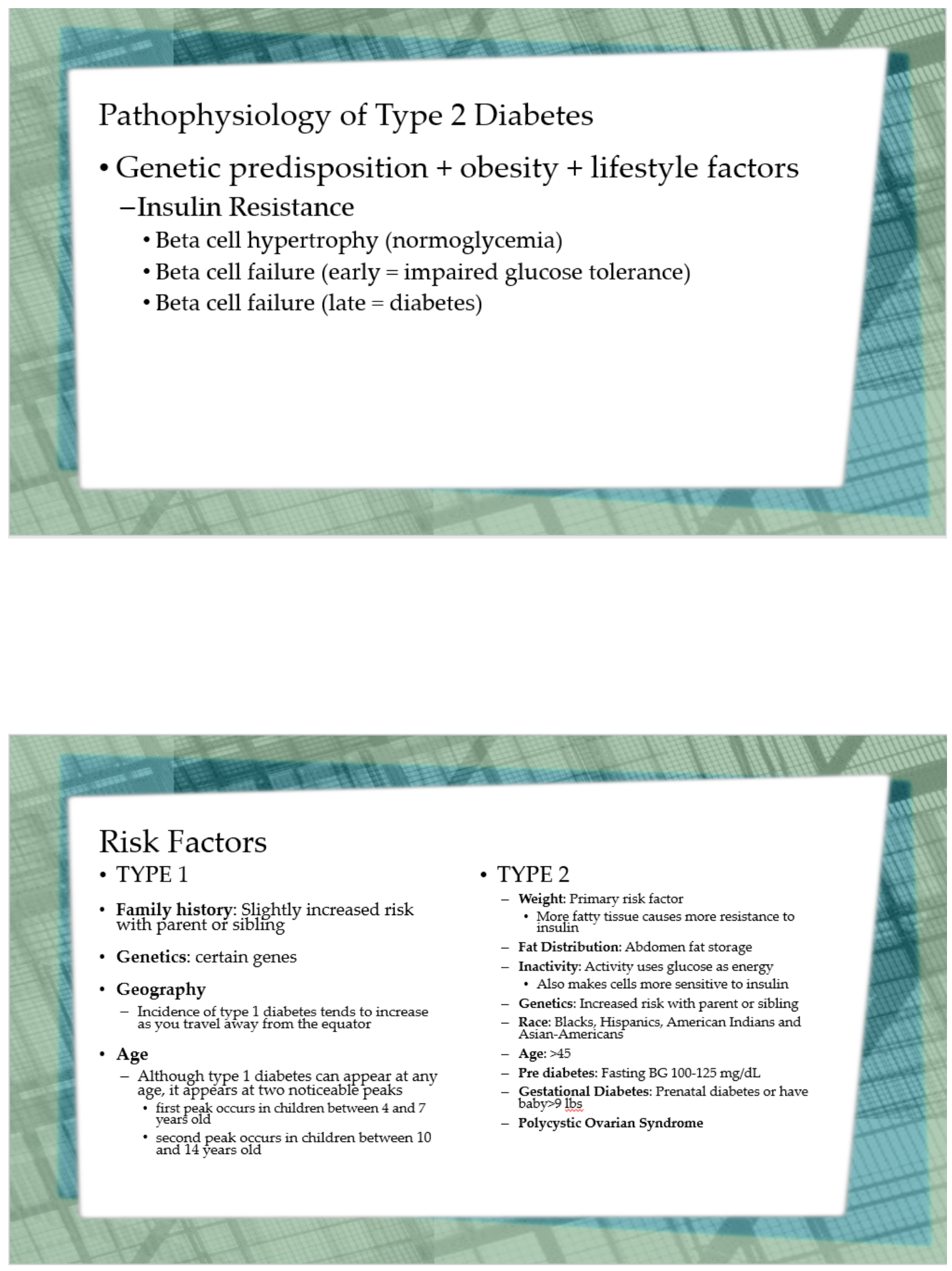

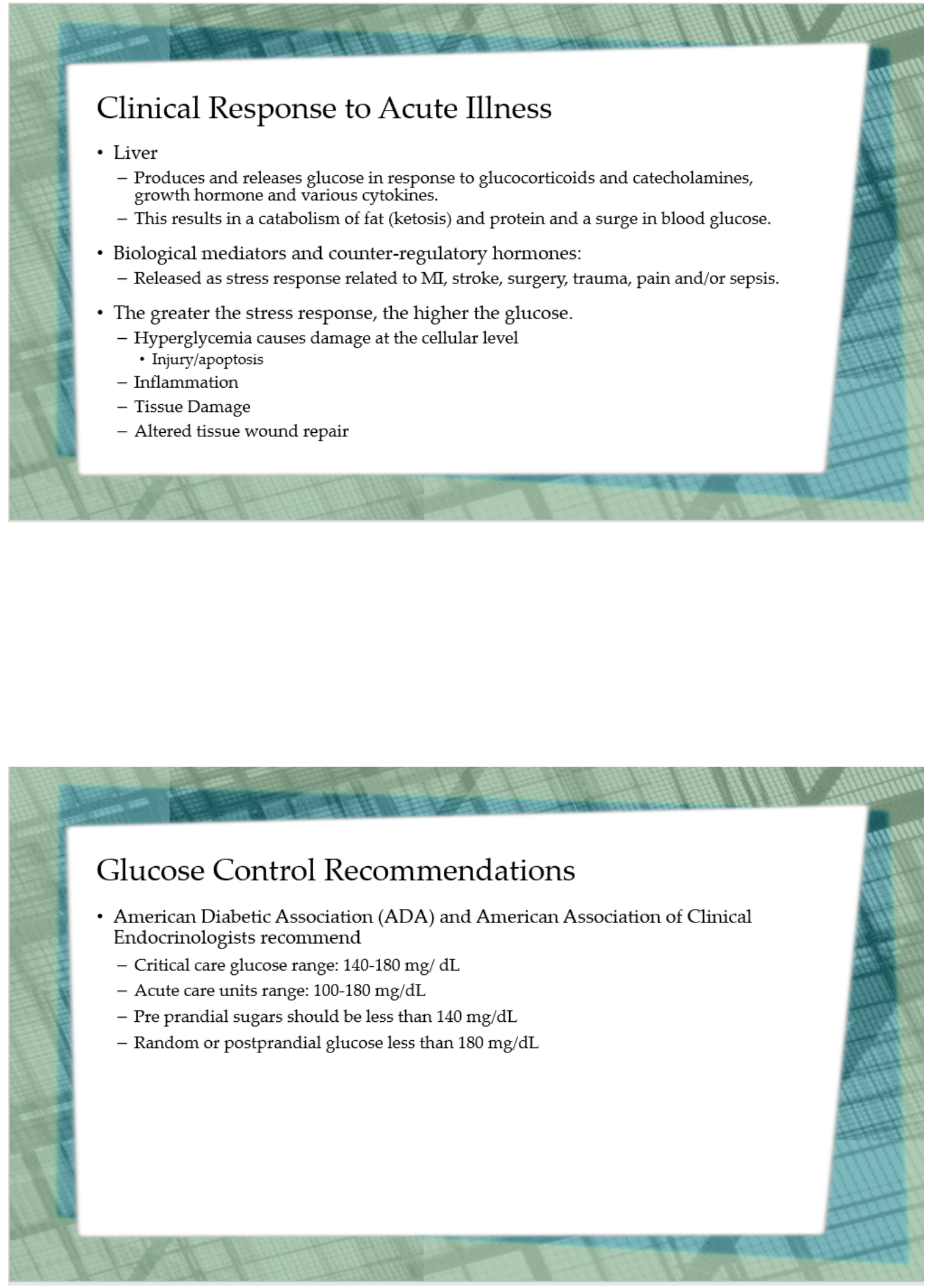


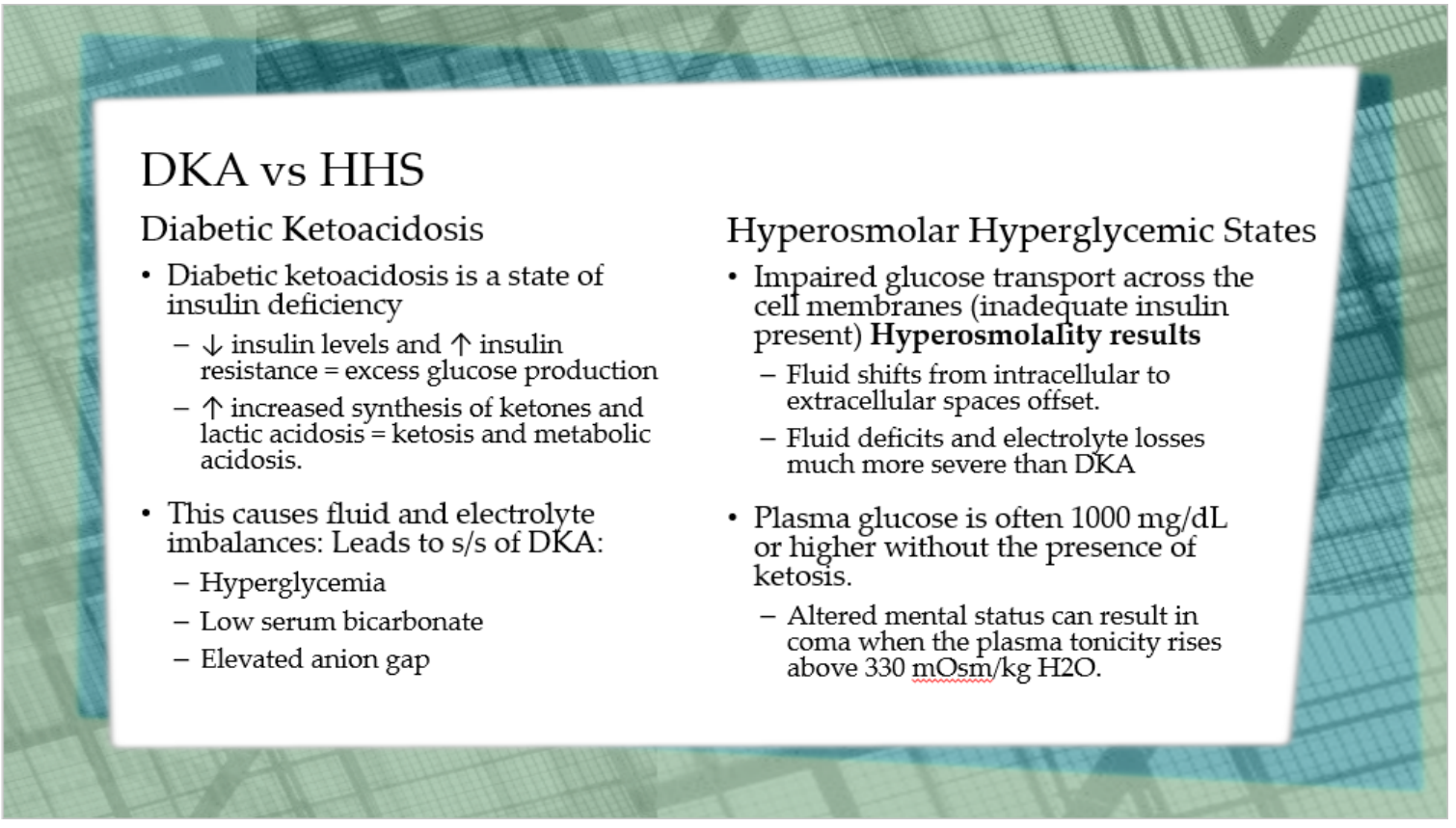

\begin{tabular}{|l|l|l|}
\hline DKA and HHS & & \\
\hline & & \\
\hline
\end{tabular}



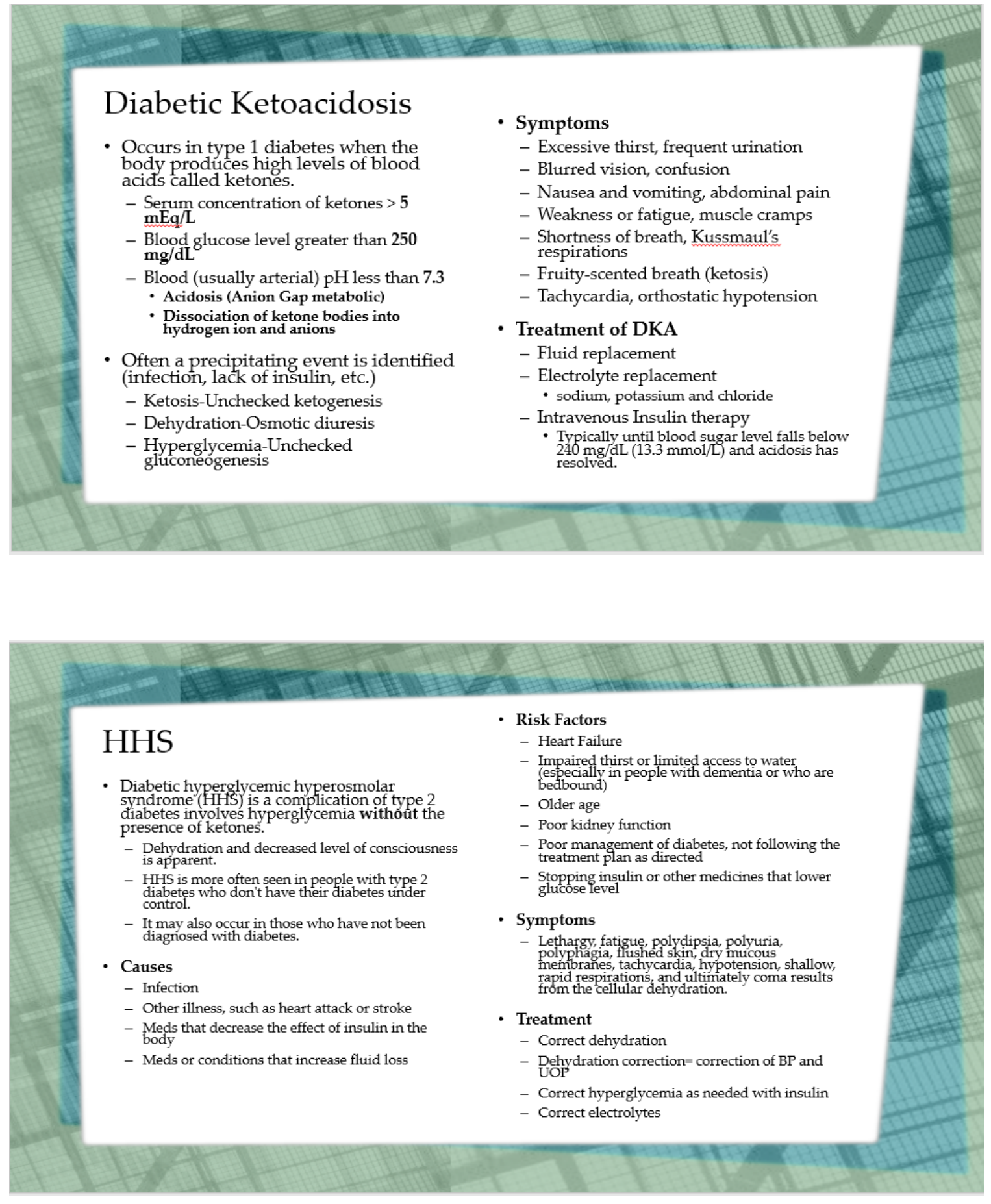

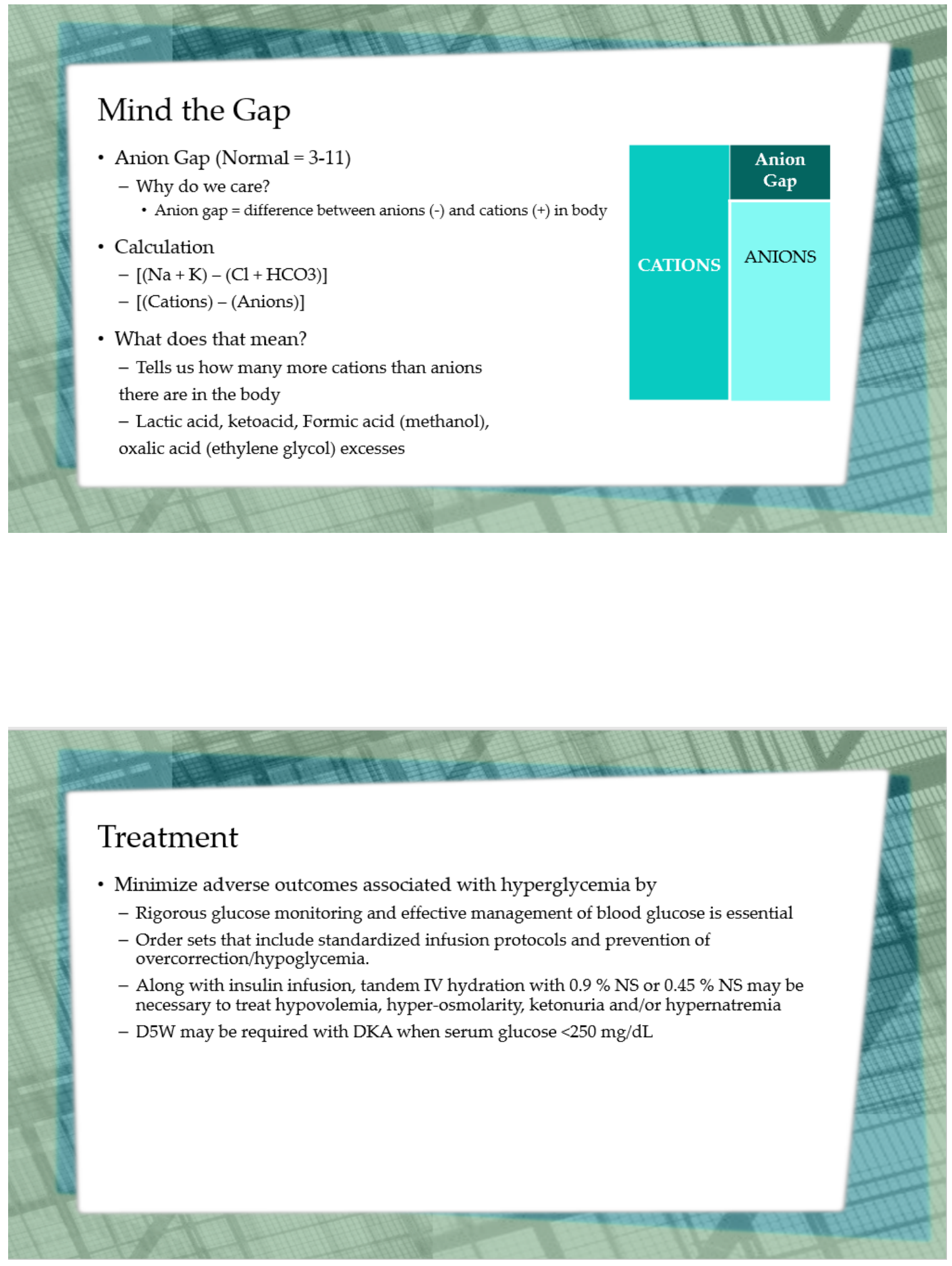

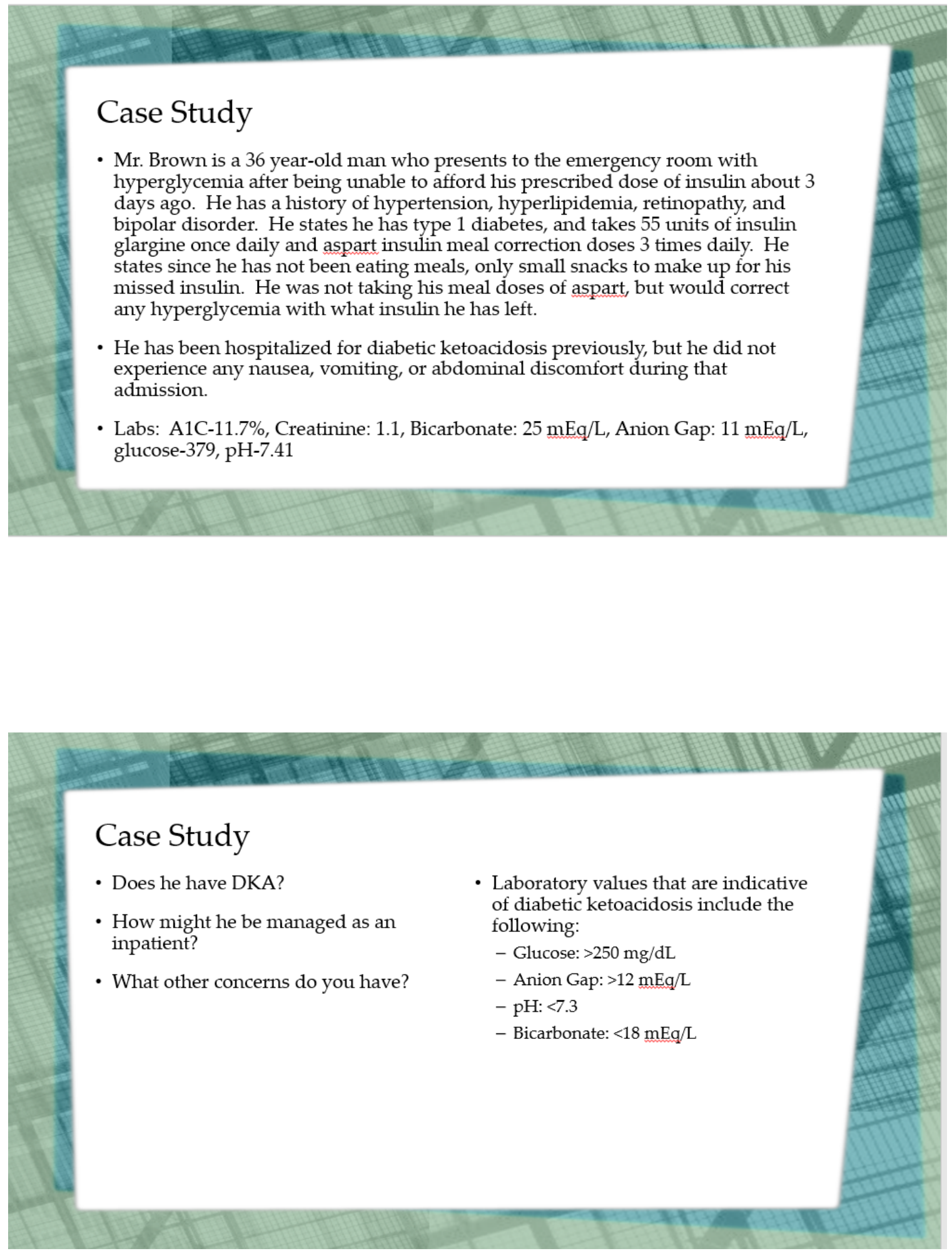

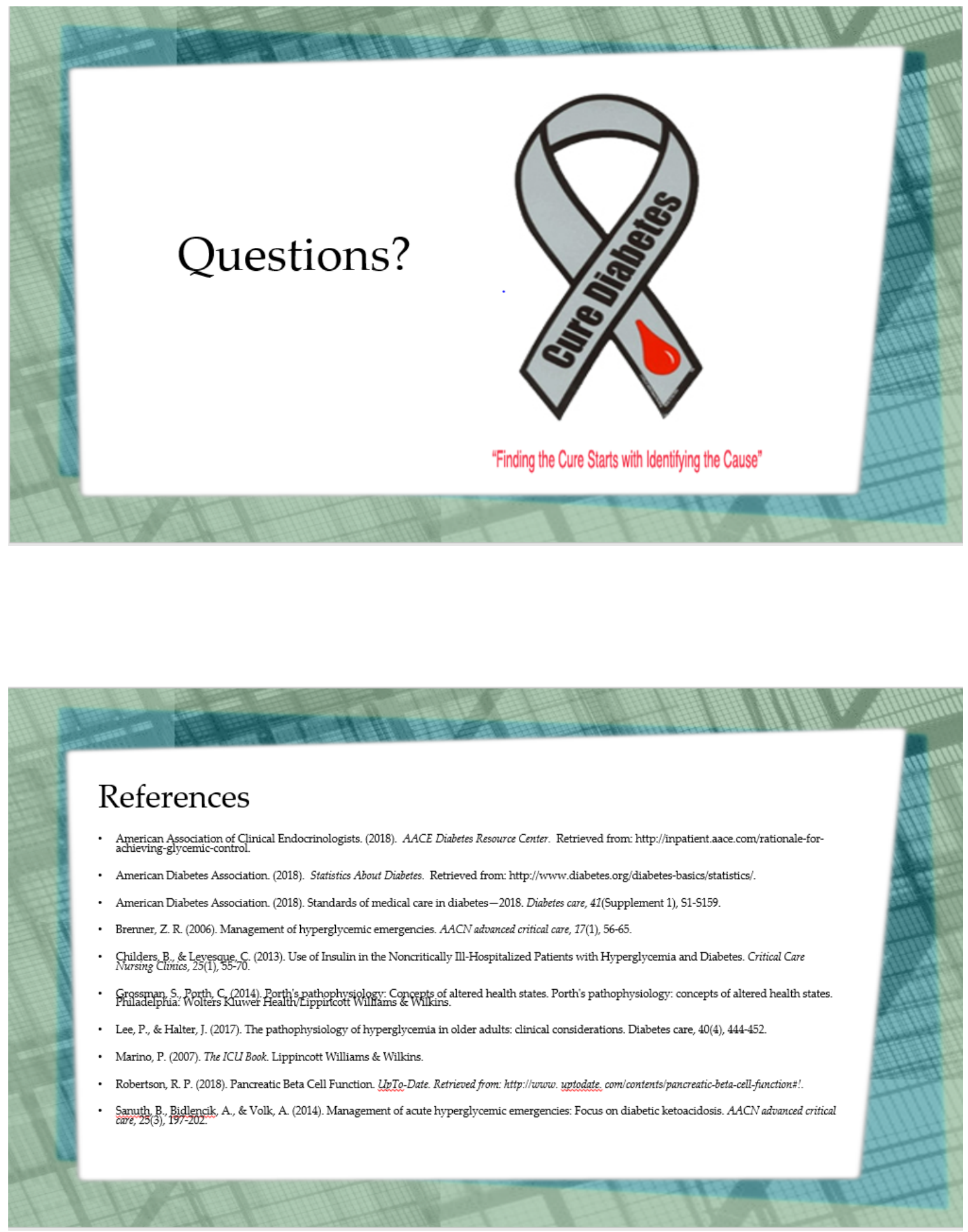
Four Digit Code

\section{Appendix D}

Please select how many years' experience you have as a nurse.
a. $<2$ years
b. $>2-6$ years
c. $>6-10$ years
d. $>10$ years

1. Diabetic ketoacidosis (DKA) is characterized by all of the following except:
a. Anion gap metabolic alkalosis
b. Hyperglycemia
c. Elevated ketones
d. None of the above

2. Which of the following characterizes hyperglycemic hyperosmolar states?
a. Low or absent ketones
b. Stupor or coma
c. Hyperglycemia is worse than DKA
d. All of the above

3. Criteria for DKA resolution include which of the following?
a. Blood glucose less than $200 \mathrm{mg} / \mathrm{dL}$
b. Bicarbonate level of $15 \mathrm{mEq} / \mathrm{L}$ or more
c. $\mathrm{pH}$ greater than 7.3
d. All of the above

4. Which of the following is one of the 4 major differences in laboratory findings in HHS as compared to DKA?

a. Acidosis in HHS is severe in comparison with DKA.

b. Serum glucose levels in HHS are generally significantly higher than those found in DKA.

c. Plasma osmolality is generally lower in HHS in comparison with DKA.

d. Ketosis in HHS is usually severe in comparison with DKA.

5. Which of the following is a major clinical feature of hyperglycemic hyperosmolar state?
a. large ketones
b. profound dehydration
c. nausea and vomiting
d. severe acidosis

6. Ketosis is
a. The metabolism of fat into fatty acids and ketones
b. Metabolism of glucose
c. Maturation of ketones
d. Catabolism of glucose 
7. Type 1 diabetes is primarily due to a
a. Genetic mutation
b. Poor diet and inactive lifestyle
c. Autoimmune response
d. Administration of a large dose of insulin in infancy

8. Type 2 diabetes is primarily a result of
a. Genetic mutation
b. Beta cell failure
c. Administration of D50
d. Substance Abuse

9. The four primary lab variations in DKA and HHS are

a. Alkalosis, ketosis, potassium, and bicarbonate

b. Alkalosis, blood glucose levels, potassium, and bicarbonate

c. Acidosis, calcium, potassium, and bicarbonate

d. Acidosis, ketosis, blood glucose levels, osmolality

10. A 58-year-old female is admitted with a diagnosis of diabetic ketoacidosis. The blood sugar is $339, \mathrm{pH}$ is 7.24 and the anion gap is 18 . The anion gap is a measure of
a. Cations plus anions
b. Cations minus anions
c. Anions plus the anion gap
d. Cations minus the anion gap 